\title{
Relative performance of empirical and physical models in assessing the seasonal and annual glacier surface mass balance of Saint-Sorlin Glacier (French Alps)
}

\author{
Marion Réveillet ${ }^{1}$, a , Delphine Six ${ }^{1}$, Christian Vincent ${ }^{1}$, Antoine Rabatel ${ }^{1}$, Marie Dumont ${ }^{2}$, Matthieu Lafaysse $^{2}$, \\ Samuel Morin ${ }^{2}$, Vincent Vionnet ${ }^{2}$, and Maxime Litt $^{1,3,4}$ \\ ${ }^{1}$ Univ. Grenoble Alpes, CNRS, IRD, Institut des Géosciences de l'Environnement (IGE, UMR 5001), 38000 Grenoble, France \\ ${ }^{2}$ Météo-France - CNRS, CNRM UMR 3589, Centre d'Etudes de la Neige, Grenoble, France \\ ${ }^{3}$ ICIMOD, G.P.O. Box 3226, Kathmandu, Nepal \\ ${ }^{4}$ Faculty of Geosciences, Utrecht University, Utrecht, the Netherlands \\ anow at: Centro de Estudios Avanzados en Zonas Áridas (CEAZA), ULS-Campus Andrés Bello, Raúl Britan 1305, \\ La Serena, Chile
}

Correspondence: Marion Réveillet (marion.reveillet@ ceaza.cl)

Received: 29 August 2017 - Discussion started: 22 September 2017

Revised: 27 January 2018 - Accepted: 14 February 2018 - Published: 16 April 2018

\begin{abstract}
This study focuses on simulations of the seasonal and annual surface mass balance (SMB) of Saint-Sorlin Glacier (French Alps) for the period 1996-2015 using the detailed SURFEX/ISBA-Crocus snowpack model. The model is forced by SAFRAN meteorological reanalysis data, adjusted with automatic weather station (AWS) measurements to ensure that simulations of all the energy balance components, in particular turbulent fluxes, are accurately represented with respect to the measured energy balance. Results indicate good model performance for the simulation of summer SMB when using meteorological forcing adjusted with in situ measurements. Model performance however strongly decreases without in situ meteorological measurements. The sensitivity of the model to meteorological forcing indicates a strong sensitivity to wind speed, higher than the sensitivity to ice albedo. Compared to an empirical approach, the model exhibited better performance for simulations of snow and firn melting in the accumulation area and similar performance in the ablation area when forced with meteorological data adjusted with nearby AWS measurements. When such measurements were not available close to the glacier, the empirical model performed better. Our results suggest that simulations of the evolution of future mass balance using an energy balance model require very accurate meteorological data. Given the uncertainties in the temporal evolution of the relevant meteorological variables and glacier surface proper-
\end{abstract}

ties in the future, empirical approaches based on temperature and precipitation could be more appropriate for simulations of glaciers in the future.

\section{Introduction}

The surface mass balance (SMB) of mountain glaciers is sensitive to climate change and contributes to the hydrological regime of high alpine catchments (IPCC, 2013). Understanding the physical processes that link local meteorology to glacier melt is necessary to properly simulate changes in glacier SMB in the context of global warming.

Several studies have successfully used various calibrated temperature-index models (TIMs) to simulate glacier melt response to meteorological forcing (Braithwaite and Olesen, 1989; Hock, 2003; Pellicciotti et al., 2005). These approaches can be used over short time periods (typically a few years), but the relevance of the calibrated parameters over longer time periods is difficult to assess for several reasons, including (i) the lack of long-term in situ meteorological measurements available close to the study site, (ii) the temporal variations of melt sensitivity to temperature and (iii) the fact that the physical link between temperature and melt is not direct (Huss et al., 2009; Gabbi et al., 2014; Réveillet 
et al., 2017). In addition, transferring parameters determined for an instrumented glacier to another site decreases model performance (Carenzo et al., 2009; Réveillet et al., 2017).

On the other hand, physical approaches consider all energy exchanges between the glacier and the atmosphere and are able to represent snowmelt spatial and temporal variability, such as those related to albedo variations that are hard to represent in TIMs. Such approaches offer higher transferability over time (e.g. MacDougall and Flowers, 2011) but require more accurate meteorological forcing (e.g. Gabbi et al., 2014). Many energy balance studies have been performed to assess surface-atmosphere interactions over ice or snow surfaces based on automatic weather stations (AWSs) deployed on glaciers (e.g. Oerlemans and Klok, 2002; Sicart et al., 2008; Senese et al., 2012; Cullen and Conway, 2015). Physically based models perform well for SMB simulations when AWS measurements are available on the study site (e.g. Six et al., 2009) and enable a quantification of each component of the energy budget and their impact on melting. However, due to the need for accurate meteorological data and the difficulty of maintaining AWSs on glaciers, this approach is generally used over short time periods (typically a few months), except for a few studies based on permanent AWSs set up on glaciers (e.g. Oerlemans et al., 2009; Sicart et al., 2011).

These physical models, using in situ meteorological data or coupled with atmospheric models (e.g. Lefebre et al., 2003; Mölg and Kaser, 2011) or forced by meteorological reanalysis (e.g. Gerbaux et al., 2005), provide an opportunity to determine the spatial distribution of SMB evolution over longer periods. The simulation of seasonal SMB changes requires accurate modelling of energy exchanges over both ice and snow surfaces. Detailed snowpack models such as Crocus (Brun et al., 1989), SNOWPACK (Lehning et al., 1999) or Snow-SVAT (Tribbeck et al., 2004) have been developed and some have been applied to glaciers (e.g. Obleitner and Lehning, 2004; Gerbaux et al., 2005; Dumont et al., 2012; Lejeune et al., 2013; Sauter and Obleitner, 2015). Due to the lack of measurements and the complexity of measuring each of the components of the energy balance (especially turbulent fluxes), physically based models are generally calibrated by adjusting certain parameters (e.g. roughness length to quantify turbulent fluxes) to fit with SMB measurements (e.g. Dumont et al., 2012).

The goal of our study is to evaluate the performance of a physical model in simulating seasonal SMB and to compare its performance and the associated uncertainties to those obtained with a TIM in order to determine the most appropriate approach for SMB simulations, especially for projections over long time periods. In the Alps, the temporal variability of the annual SMB is mainly driven by summer SMB variability (e.g. Six and Vincent, 2014). For this reason, many studies have focused on ablation modelling. However, simulated summer SMB and associated uncertainties strongly depend on the winter SMB (Réveillet et al., 2017), highlighting the need for a quantification of the sensitivity of annual SMB to both seasonal components.

For these purposes, we use the detailed SURFEX/ISBACrocus snowpack model (Vionnet et al., 2012), driven by SAFRAN meteorological reanalysis data (Durand et al., 2009), to simulate the SMB of Saint-Sorlin Glacier (French Alps). We first assess the accuracy of SAFRAN meteorological reanalysis data at this high-elevation site using all available glaciological and meteorological measurements performed since 2005 on Saint-Sorlin Glacier. Then, the surface energy and mass balance model is calibrated using the measured energy balance to ensure that all the energy balance components are accurately represented. Next, the SMB model is evaluated using 20 years of seasonal SMB measurements (Sect. 4.1.1) and results are compared to those obtained with TIMs (Sect. 4.1.2). Section 4.1.3 focuses on annual SMB sensitivity to seasonal SMB. Finally, Crocus model sensitivity to meteorological forcing, calibration and topographic parameters is analysed in Sect. 4.2.

\section{Study site and data}

\subsection{Study site: Saint-Sorlin Glacier}

Saint-Sorlin Glacier is located in the Grandes Rousses massif in the French Alps (Fig. 1) and is monitored by the GLACIOCLIM programme (https://glacioclim.osug.fr). Saint-Sorlin Glacier covers a surface area of roughly $2.5 \mathrm{~km}^{2}$. The glacier flows along slopes with highly variable aspects, descending from 3460 to $2700 \mathrm{ma}$ a.s.l. More details on the topographic characteristics of this glacier are provided in Six and Vincent (2014).

\subsection{Glaciological measurements over the period October 1996-2015}

\subsubsection{Seasonal surface mass balance measurements}

Seasonal SMB has been monitored since 1995 using the glaciological method (Cuffey and Paterson, 2010) at about 30 measurements points (Fig. 1). During summer (i.e. from around 15 April to 15 October, corresponding to the ablation season), the glacier is regularly visited and monthly ablation measurements are available. The uncertainties of the SMB measurements are evaluated at approximately $\pm 0.20 \mathrm{mw}$.e. $\mathrm{yr}^{-1}$ for winter surface mass balance (winter SMB) and $\pm 0.15 \mathrm{~m}$ w.e. $\mathrm{yr}^{-1}\left(0.30 \mathrm{mw}\right.$.e. $\left.\mathrm{yr}^{-1}\right)$ for summer surface mass balance (summer SMB) on ice (snow/firn) (Thibert et al., 2008). The monitoring network covers a large part of the glacier both in the accumulation and ablation areas (Fig. 1). Winter SMBs are measured at each point located in the accumulation and ablation areas in late April using snow cores and density measurements. Summer SMBs are quantified using stakes inserted in the ice/snow. 

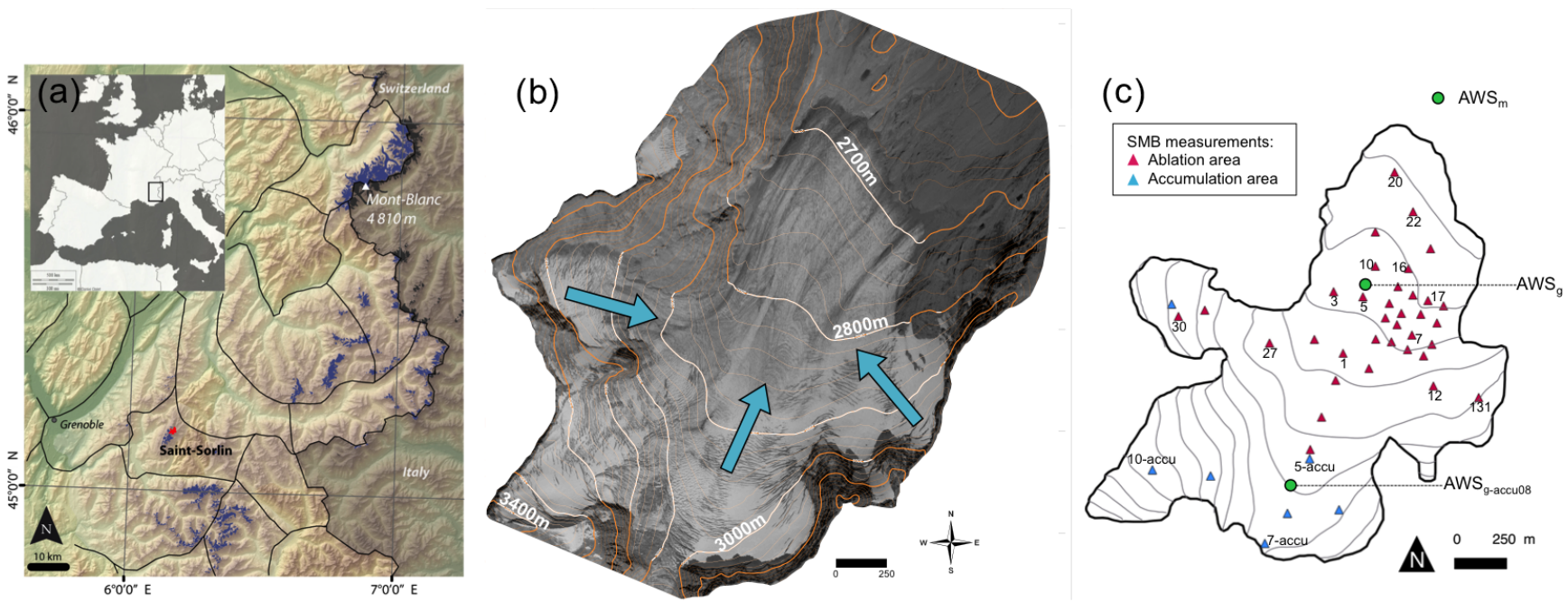

Figure 1. (a) Location of Saint-Sorlin Glacier in the French Alps. French glaciers are shown in blue except for Saint-Sorlin Glacier, used for the present study, which is in red. Black lines represent SAFRAN massif outlines (adapted from Rabatel et al., 2016). (b) Aerial photo of Saint-Sorlin Glacier. Blue arrows indicate the three main glacier flow lines. (c) Map of Saint-Sorlin Glacier with the network of in situ SMB measurements (blue triangles in the accumulation area and red triangles in the ablation area). Locations of automatic weather stations used in this study are represented by green circles.

\subsubsection{Digital elevation models}

We used three digital elevation models (DEMs) (1998, 2007 and 2014) to account for the changes in glacier geometry during the studied period. These DEMs were derived from aerial photogrammetry and have a $10 \mathrm{~m}$ spatial resolution. For consistency with the resolution of the atmospheric data described in Sect. 2.3.3, they were, for this study, upscaled to $200 \mathrm{~m}$ resolution using the kriging method (based on the default linear variogram) of SURFER mapping software (Golden Software, LLC).

\subsection{Meteorological data}

\subsubsection{Automatic weather stations}

In the framework of GLACIOCLIM, a permanent AWS has been in operation since August 2005 on the foreland of SaintSorlin Glacier (noted $\mathrm{AWS}_{\mathrm{m}}$ in Fig. 1c). This AWS records $2 \mathrm{~m}$ air temperature and relative humidity (the common sensor is housed in a mechanically aspirated shield), incoming and reflected shortwave radiation, incoming and outgoing longwave radiation, and wind speed and direction with a half-hour time step. $\mathrm{AWS}_{\mathrm{m}}$ data were quality-checked to avoid any problem related to a sensor malfunction: missing data were detected and reported, unrealistic values were removed and the series was compared with series from MétéoFrance network stations in the valley to identify potential bias. A summary of the meteorological conditions at $\mathrm{AWS}_{\mathrm{m}}$ is given in the Supplement. An additional meteorological station (noted $\mathrm{AWS}_{\mathrm{g}}$ in Fig. 1c) was set up in the ablation area of the glacier during each of the three summer field cam- paigns (2006, 2008 and 2009). It will be referred to hereafter as $\mathrm{AWS}_{\mathrm{g} 06}, \mathrm{AWG}_{\mathrm{g} 08}$ and $\mathrm{AWS}_{\mathrm{g} 09}$ to distinguish between the different years. Note that during the 2008 field campaign, another AWS was set up in the accumulation area (noted $\mathrm{AWS}_{\mathrm{g} \text {-accu08 }}$ in Fig. 1c). Details relative to the location, the dates of records and the different sensors of these AWSs are reported in Table 1. Stations on the glaciers are mounted on masts inserted in the ice. Due to ice melt, instrument heights are not constant over time. However, at each station (except for $\mathrm{AWS}_{\mathrm{g} \text {-accu08, where melt is limited), a sonic ranger was }}$ set up and helped determine the melt over each recorded time step. The heights of the instrument were then adjusted in our simulation using the melt determined by the sonic ranger. Every 10 to 15 days, instruments were re-adjusted manually to a set height of $2 \mathrm{~m}$. Moreover, as the surface slope angles were small at each station and because the radiometers were not found to be far from horizontal during field visits, no slope correction was applied to the measured shortwave radiation.

\subsubsection{Eddy covariance system and atmospheric mast}

In 2006, a summer field campaign was also conducted to measure turbulent fluxes using the eddy covariance (EC) method (Table 1). During this campaign (9 July to $28 \mathrm{Au}-$ gust 2006), an eddy covariance system measuring the highfrequency $(20 \mathrm{~Hz})$ wind speed components, sonic temperature and specific humidity was fixed on a mast in the ablation zone next to $\mathrm{AWS}_{\mathrm{g}}$. The CSAT instrument was installed $2.00 \mathrm{~m}$ above the surface. The melt ranges roughly between 30 and $40 \mathrm{~cm}$, with a maximum of $80 \mathrm{~cm}$ depending on the 


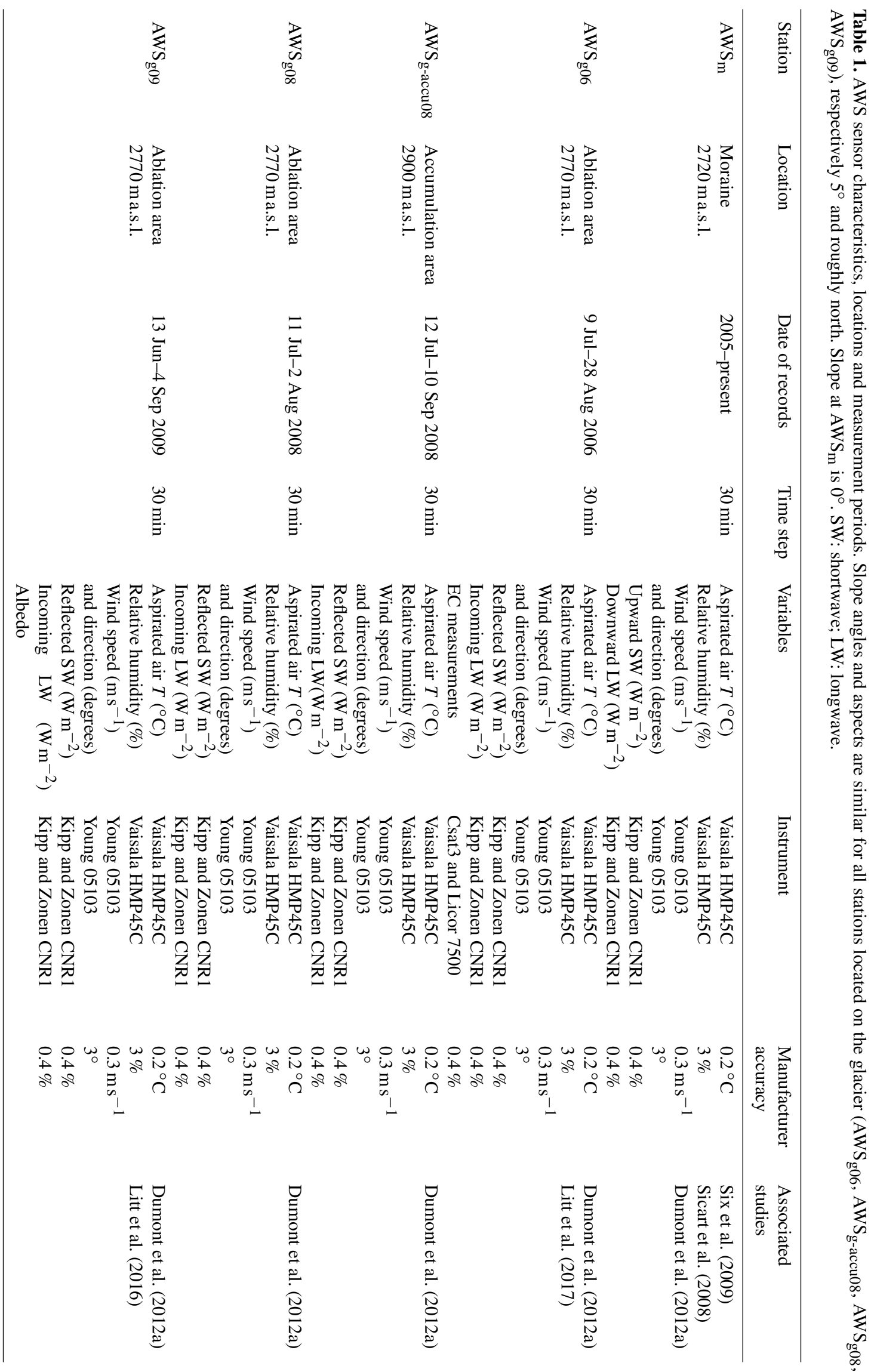


month and the time between two visits. Every 10 to 15 days, the instrument was re-adjusted manually to a set height of $2 \mathrm{~m}$. More details on the sensors, the field campaign and data processing are available in Litt et al. (2017).

\subsubsection{Raw SAFRAN reanalysis data}

Since AWS records on glaciers are limited in time and scarcely distributed, the near-surface meteorological forcing data are estimated by meteorological reanalyses. In this study, we used the SAFRAN meteorological re-analysis system (Durand et al., 2009). SAFRAN data are provided using atmospheric vertical profiles simulated by an atmospheric model (ERA-40 reanalysis until 2001 and ARPEGE operational model after 2002). Results are then corrected by optimal interpolation with observed meteorological data from various sources (automatic weather stations, manual observations carried out in the climatological network or at ski resorts, remotely sensed cloudiness, atmospheric upper-level sounding). Note that surface observations that could be used to correct data are scarce at very high altitudes (i.e. above 2000 ma.s.1.).

SAFRAN outputs include hourly meteorological variables ( $2 \mathrm{~m}$ air temperature and relative humidity, precipitation amounts and phases, incoming direct and diffuse shortwave radiation, incoming longwave radiation, wind speed, cloudiness) that are assumed to be homogeneous within a given massif (in particular within the Grandes Rousses massif where the Saint-Sorlin Glacier is located, Fig. 1a) and depend only on altitude (one data point every $300 \mathrm{~m}$ ) and aspect (seven orientations available: N, NE, NW, S, SW, SE and "Flat"). The direct solar radiation is provided for an infinite flat area but can be easily projected for any aspect and slope (Lafaysse et al., 2011) using the Crocus model (see Sect. 3.1.1). Shading from surrounding topography is taken into account in the computation of shortwave radiation, but the impact of emitted longwave radiation and reflected shortwave radiation by surrounding slopes is not considered.

SAFRAN outputs are available in $300 \mathrm{~m}$ elevation steps. In our study, they were linearly interpolated (following the vertical and horizontal axes) on the $200 \mathrm{~m}$ horizontal resolution grid encompassing the glacier.

\subsubsection{Adjusted SAFRAN data}

SAFRAN data were compared to the $\mathrm{AWS}_{\mathrm{m}}$ measurements over 10 years (2006-2015) and to the available $\mathrm{AWS}_{\mathrm{g}}$ measurements. Biases were adjusted and the influences of all corrections mentioned below on the simulated SMB are discussed in Sect. 4.2. SAFRAN and AWS $\mathrm{S}_{\mathrm{m}}$ hourly air temperatures over the ablation and accumulation seasons are well correlated $-R^{2}=0.98$ (summer) and 0.99 (winter), both significant at the $99 \%$ confidence level (Student's $t$ test), and the root-mean-square errors (RMSEs) are $0.7^{\circ} \mathrm{C}$ (summer) and $0.76^{\circ} \mathrm{C}$ (winter). Hourly SAFRAN relative humidity is also in good agreement with the $\mathrm{AWS}_{\mathrm{m}}$ data $\left(R^{2}=0.74\right.$, significant at the $95 \%$ confidence level, and RMSE $=13.6 \%$ ). The comparison between SAFRAN and $\mathrm{AWS}_{\mathrm{m}}$ incoming longwave radiation indicates an overestimation of SAFRAN data for low cloudiness conditions. This can be caused by highaltitude clouds, which are not considered in SAFRAN reanalysis and an incorrect vertical discretization of the atmosphere in SAFRAN. As proposed by Dumont et al. (2012), we corrected the longwave incident radiation ( $\mathrm{LW}$ in $\mathrm{W} \mathrm{m}^{-2}$ ) by implementing a linear function depending on SAFRAN cloudiness (ranging from 0 to 1 ) (Eq. 1):

$\mathrm{LW}_{\text {corrected }}=\mathrm{LW}_{\text {SAFRAN }}-(a \times$ Cloudiness $+b)$,

where $a=-0.56$ and $b=38 \mathrm{~W} \mathrm{~m}^{-2}$ are empirical parameters, calibrated with $\mathrm{AWS}_{\mathrm{m}}$ measurements. This correction was calibrated over the 2006-2015 period and applied over the 1996-2015 period. Using this correction, the correlation between $\mathrm{AWS}_{\mathrm{m}}$ incoming LW radiation and corrected $\mathrm{LW}$ radiation from SAFRAN increased the correlation from $R^{2}=0.71$ to $R^{2}=0.83$ and the RMSE decreased from 44.3 to $29.7 \mathrm{~W} \mathrm{~m}^{-2}$. Correlations between daily incoming shortwave radiation $\left(R^{2}=0.81\right)$ are significant at the $99 \%$ confidence level (Student's $t$ test) and RMSE $=77.2 \mathrm{~W} \mathrm{~m}^{-2}$.

A poor correlation $\left(R^{2}=0.19, \mathrm{RMSE}=3.8 \mathrm{~m} \mathrm{~s}^{-1}\right)$ between SAFRAN wind speed (considered at $2 \mathrm{~m}$ ) and measured values at $\mathrm{AWS}_{\mathrm{m}}$ (at $\sim 2 \mathrm{~m}$ ) is observed and is mainly due to an underestimation of strong winds by SAFRAN. Differences between $\mathrm{AWS}_{\mathrm{m}}$ and SAFRAN wind speed range from 0.9 to $21 \mathrm{~m} \mathrm{~s}^{-1}$ with a mean value of $4.3 \mathrm{~m} \mathrm{~s}^{-1}$. This underestimation is likely due to both non-consideration of katabatic wind and local effects due to orography (Dumont et al., 2012). As mentioned in Litt et al. (2017), when large-scale atmospheric forcing was strong, intense downslope winds were observed, aligned with the main glacier flow (i.e. coming from the south; see Fig. 1b). The wind speed measured at $\mathrm{AWS}_{\mathrm{m}}$ (glacier foreland) were first compared to the wind measured at $\mathrm{AWS}_{\mathrm{g} 06}$ and $\mathrm{AWS}_{\mathrm{g} 09}$. Since the correlation between the measured wind speed on the foreland and on the glacier is high $\left(R^{2}=0.97\right.$, RMSE $\left.=1.7 \mathrm{~m} \mathrm{~s}^{-1}\right)$, we assumed the wind speed measured at $A W S_{m}$ to be representative at the glacier scale and used it to replace SAFRAN wind speed estimates in this study. However, data are limited to the 2006-2015 period. Outside this period (over 1996-2005), the SAFRAN wind speed was corrected using a quantilemapping method (Déqué, 2007; Gobiet et al., 2015). This method was chosen because it is considered to be one of the most efficient bias adjustment methods available (e.g. Gobiet et al., 2015). Percentiles of the observed distribution $\left(\mathrm{AWS}_{\mathrm{m}}\right.$ measurements) and the SAFRAN distribution are calculated using every data of a given month and for each month over the 2006-2015 period. A linear method was used for mapping and extrapolated data over the minimum/maximum observed quantile were estimated with a linear function. The resulting mapping function of the quantile-quantile plot was 


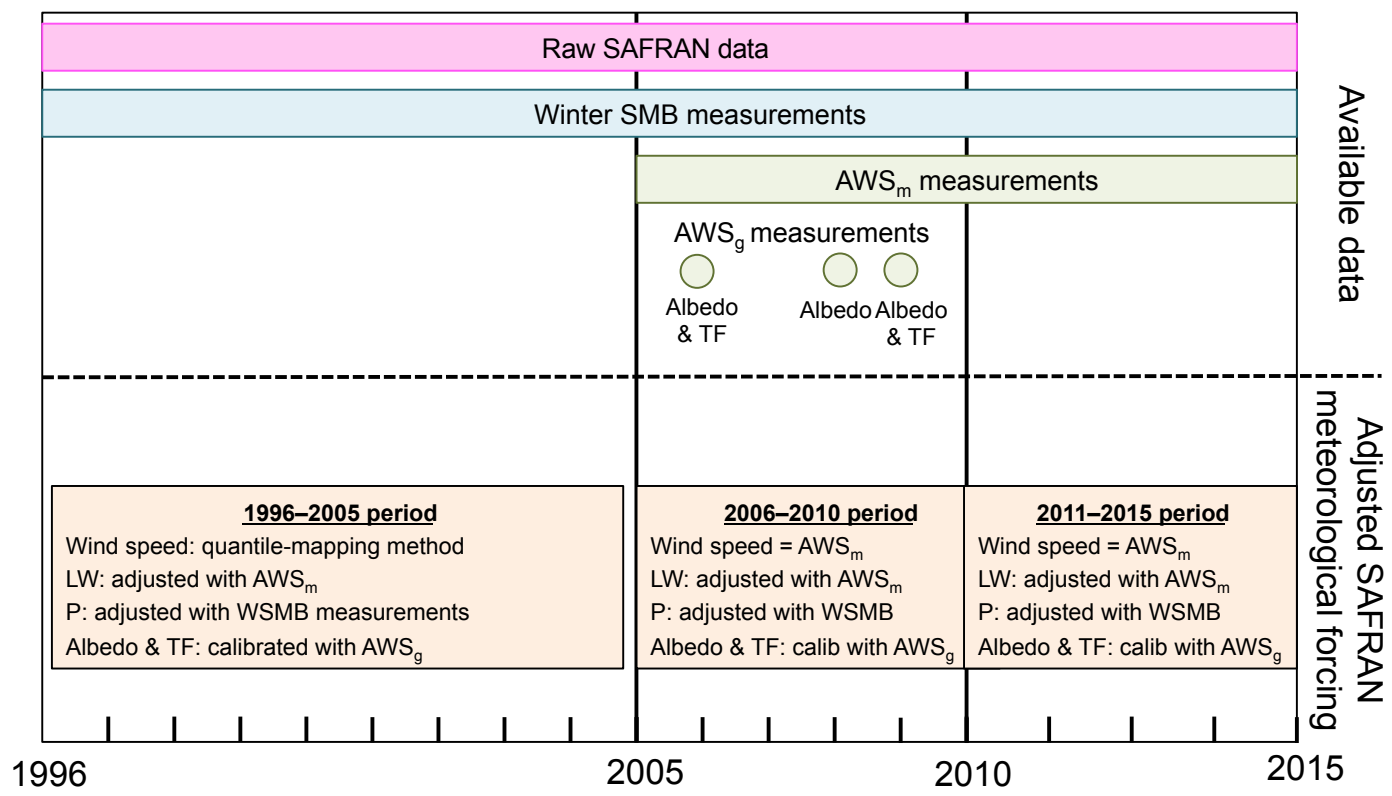

Figure 2. Summary of available meteorological data and the adjustments of the raw SAFRAN data, depending on the study period ( $P$ : precipitation; TF: turbulent fluxes).

used to adjust the SAFRAN wind speed distribution over the 1996-2005 period.

Finally, SAFRAN-cumulated winter precipitation over each winter was compared to the winter SMBs measured at each accumulation measurement site. As already mentioned in previous studies (Gerbaux et al., 2005; Dumont et al., 2012), using SAFRAN raw data leads to a significant underestimation of the winter SMB. The accumulation amount was adjusted based on the methodology developed in previous studies (Vincent, 2002; Gerbaux et al., 2005; Dumont et al., 2012; Réveillet et al., 2017). For each winter, individual winter SMB measurements were first used to compute multiplication factors for SAFRAN precipitation. The multiplication factors were then spatially interpolated over the entire glacier surface area (kriging method) to obtain an annual map of multiplicative factors. These factors were then used to correct solid and liquid precipitation. The factors varied from 1.2 to 2.1 depending on both the year and the site. Applying these factors led to an increase in winter SMB ranging from 0.05 to $1.64 \mathrm{mw}$ w.e. $\mathrm{yr}^{-1}$ depending on the site (with a mean of $0.46 \mathrm{mw}^{2}$.e. $\mathrm{yr}^{-1}$ ).

All adjustments of the raw SAFRAN data described below are summarized in Fig. 2. The impact of these corrections on the simulated SMB is discussed in Sect. 4.2.2.

\section{Methodology: model descriptions and evaluation metrics}

\subsection{Model descriptions}

\subsubsection{Crocus model}

The Crocus snowpack model, implemented as one of the snow scheme options of the SURFEX/ISBA land surface model (Masson et al., 2013), was originally developed by Météo-France to simulate seasonal snowpack and to assist in avalanche hazard forecasting over the French mountain ranges (Brun et al., 1989; Vionnet et al., 2012). Crocus is a full energy balance, one-dimensional snowpack model, driven by meteorological variables including temperature, shortwave radiation, longwave radiation, specific humidity, rainfall and snowfall rates and wind speed. It simulates a layered snowpack with a Lagrangian representation, each layer being characterized by its thickness, density, temperature, liquid water content and two semi-empirical variables to describe the snow/ice microstructure. The variables are grain size/dendricity and sphericity (see Vionnet et al., 2012, for more details). Their values are specified for glacier ice. The specified values only impact the calculation of albedo/light penetration depth, which is constant for ice. The number of numerical snow layers evolves with time to tend towards an idealized prescribed thickness profile that is appropriate for the computation of an accurate energy balance (thinner layers close to the surface) but that avoids the aggregation of snow layers with different microstructural properties. The model solves the heat diffusion equation in the snowpack at a $15 \mathrm{~min}$ 
time step considering the different energy fluxes between the surface and the atmosphere and between the bottom of the snowpack and the soil. Physical processes such as solar radiation absorption, liquid water percolation, snow metamorphism and settlement are also considered by the model. The snowpack model can be used on icy surfaces, considering an ice layer as a specific snow layer with a density of $917 \mathrm{~kg} \mathrm{~m}^{-3}$ (Gerbaux et al., 2005; Lejeune et al., 2007; Dumont et al., 2012). The specific parameterizations used in our study (albedo and roughness length) will be described in detail below. A more general presentation of Crocus can be found in Brun et al. (1992) and Vionnet et al. (2012).

In the initial version of Crocus, solar radiation is handled in three separate spectral bands ([0.3-0.8], [0.8-1.5] and $[1.5-2.8] \mu \mathrm{m})$, and albedo is computed for each band as a function of the snow properties: grain size, shape and age (Brun et al., 1992). In this initial version, snow albedo ranges from 1 to 0.7 in the UV and visible range $([0.3-0.8] \mu \mathrm{m})$ and depends on the optical diameter and on the amount of lightabsorbing impurities, the latter being parameterized with respect to the age of snow (with a time constant of 60 days). In our study, the minimum snow albedo is set to 0.5 to consider older snow with higher impurity content (Cuffey and Patterson, 2010) and the time constant for the impurities parameterization is reduced to 20 days. In particular, firn albedo is considered as old snow albedo. Ice albedo is constant with time for all the considered spectral bands. Values are set to $[0.23,0.16,0.05]$, based on previous studies on Saint-Sorlin Glacier (Gerbaux et al., 2005; Dumont et al., 2012). Note that albedo measurements performed at $\mathrm{AWS}_{\mathrm{g} 06}, \mathrm{AWG}_{\mathrm{g} 08}$ and $\mathrm{AWS}_{\mathrm{g}-\mathrm{accu} 08}$ were used to calibrate and validate ice and snow albedo in the model (see Sect. 4.2.3.2).

In Crocus, the sensible and latent heat fluxes (respectively $H$ and LE) are calculated using the bulk aerodynamic approach, including a stability correction (Brutsaert, 1982). The two fluxes are parameterized using an effective surface roughness length $z_{0}$ (Vionnet et al., 2012), with different values for snow and ice surfaces. Note that this roughness length $z_{0}$ is considered as an effective value used in the model to fix the aerodynamic $\left(z_{\mathrm{m}}\right)$, temperature $\left(z_{\mathrm{t}}\right)$ and humidity $\left(z_{\mathrm{q}}\right)$ roughness values, following the approximation: $z_{0}=z_{\mathrm{m}}=10 z_{t}=10 z_{q}$. The choice of appropriate values for $z_{0}$ over ice $\left(z_{0 \text { ice }}\right)$ for Saint-Sorlin Glacier is presented in Sect. 4.2.3.1. As no turbulent flux measurements are available for the snow surface, the snow roughness length $\left(z_{0 \text { snow }}\right)$ is arbitrarily fixed at $0.1 \mathrm{~mm}$ (Gromke et al., 2011).

\subsubsection{Temperature-index model}

The empirical model selected in this study is the ATI (Alternative Temperature-Index) model proposed by Réveillet et al. (2017). In this approach, the daily melt is computed as follows:
$M=\mathrm{Tf}_{\text {ice } / \text { snow }} \times T+\mathrm{If}_{\text {ice } / \text { snow }} \times \mathrm{IPOT}$,

where $\mathrm{Tf}_{\text {snow } / \text { ice }}$ is the temperature factor (mw.e. day ${ }^{-1}{ }^{\circ} \mathrm{C}^{-1}$ ) which depends on the surface condition (i.e. ice or snow), $T$ is the mean daily air temperature $\left({ }^{\circ} \mathrm{C}\right), \mathrm{If}_{\text {snow } / \text { ice }}$ is the radiation factor $\left(\mathrm{m}^{3}\right.$ w.e. day $\left.{ }^{-1} \mathrm{~W}^{-1}\right)$ which also depends on the surface condition (i.e. ice or snow) and IPOT is the potential clear-sky direct solar radiation $\left(\mathrm{W} \mathrm{m}^{-2}\right)$ calculated following Hock (1999). Melt can occur when the sum of the two terms of the equation is positive, meaning that melt can occur even if $T$ is $<0^{\circ} \mathrm{C}$. In this approach, $\mathrm{If}_{\text {snow/ice }}$ represents the energy fluxes related to solar radiation, which differ for snow and ice, but are assumed constant in time (i.e. no temporal change in the albedo of the snow or ice is taken into account). Tf represents the temperature-dependent energy fluxes such as turbulent fluxes or LW radiation. Empirical factors were calibrated with punctual SMB measurements performed on Saint-Sorlin Glacier over the period 1995-2012 (more details on the model and the calibration can be found in Réveillet et al., 2017).

\subsection{Evaluation metrics}

\subsubsection{Model evaluation method}

The Crocus model was applied over the 1996-2015 period and evaluated over three distinct time periods, depending on the available AWS measurements (Fig. 2): (i) a calibration period (2006-2010), over which it was possible to correct both meteorological forcing and model parameterization (albedo and roughness length) using $\mathrm{AWS}_{\mathrm{g}}$ and $\mathrm{AWS}_{\mathrm{m}}$ measurements, (ii) the 2011-2015 period over which it was possible to correct only meteorological forcing using $\mathrm{AWS}_{\mathrm{m}}$ measurements, and finally (iii) the 1996-2005 period over which no corrections were possible, due to the absence of AWS measurements. Results of annual, winter and summer mass balance simulation using Crocus are presented in Sect. 4.1.1.

Crocus model simulations were then compared to those obtained from the ATI TIM. The ATI model was forced with the same winter SMB simulated by Crocus, to compare the ability of the two models to simulate summer SMB only. Note that in the ATI model, summertime snowfalls are deduced from SAFRAN data. Comparisons were performed over two periods: (i) the period for which AWS measurements were available (2006-2015) and (ii) the period without AWS measurements available (1996-2005).

Simulations were performed with a $200 \mathrm{~m}$ DEM resolution (see Sects. 2.2.2 and 2.3.3) and grid cells corresponding to stake locations were extracted for comparison between modelled and measured SMBs. Note that a $200 \mathrm{~m}$ resolution was chosen as a compromise to be sufficiently precise to consider the spatial variation of Saint-Sorlin Glacier (in particular the variation of aspect) and capture variability between 
stakes, while maintaining relevance regarding the meteorological forcing (given that values are available every $300 \mathrm{~m}$ of elevation). Performance was evaluated by comparing summer SMB simulated by the ATI and Crocus models to summer SMB measurements of each stake located in the ablation and accumulation areas. Note that comparisons were made over the exact same period, determined by SMB measurement dates. The results are presented in Sect. 4.2.3.

Finally, the sensitivity of annual SMB to both winter and summer SMB was assessed using the Crocus model at various stakes in the ablation area. First, we considered averaged winter conditions over the accumulation period (from 1 October to 15 April) by computing the average of the 20 available winters (1996 to 2015). Then, based on this averaged winter, 20 simulations of annual SMB were performed using each of the 20 summer conditions (1996-2015).

Next, we assessed the sensitivity of annual SMB to winter SMB. We considered an averaged summer by computing the mean of the SAFRAN corrected re-analysis of the 20 summers available (1996-2015). Simulations were performed using the 20 winter conditions available. The results are presented in Sect. 4.1.3.

\subsubsection{Analysis of SMB sensitivity to Crocus parameterization}

\section{DEM}

First, we investigated the effect of the spatial resolution of the DEM. For this purpose, the numerical simulations were performed with a $50 \mathrm{~m}$ resolution grid size, based on the 2007 DEM, and were compared with the results obtained using the same DEM with a $200 \mathrm{~m}$ resolution grid. Second, the impact of changes in glacier surface topography with time was evaluated by performing simulations over the 2006-2010 period using the three DEMs (1998, 2007 and 2014). To evaluate these sensitivities, summer SMBs simulated by Crocus were compared to summer SMB measurements at each stake and the results are presented in Sect. 4.2.1.

\section{Meteorological forcing}

To test the impact of the correction made on the longwave radiation, wind speed and precipitation, simulations were performed using a raw SAFRAN forcing and the adjusted SAFRAN forcing described in Sect. 2.3.4. Evaluation involved comparing SMBs simulated by Crocus with SBMs measured at each stakes, over the 2006-2010 period. The results are presented in Sect. 4.2.2. Regarding the precipitation, two additional adjustment methods were used. The first is based on the use of a single mean correction factor, computed using all available winter SMBs (over the 1996-2015 period). The second method is based on the use of a temporally averaged spatialized map of multiplicative factors based on the 20 years of available measurements (as proposed by Gerbaux et al., 2005 and Dumont et al., 2012).

\section{Crocus parameters}

In the Crocus version used in this study, both surface roughness and albedo were calibrated using AWS measurements. Sensitivity tests were performed by varying these variables to estimate the uncertainties when no measurements are available. The effective roughness length values were varied arbitrarily by a factor of 1 to 100 and the ice albedo of the spectral band [0.3-0.8] $\mu \mathrm{m}$ were varied from 0.16 to 0.32 (in agreement with Oerlemans et al., 2009). Simulations were performed at different stakes for the 2006-2010 period. The results are presented in Sect. 4.3.3.

\section{Results and discussion}

\subsection{Surface mass balance modelling}

\subsubsection{Crocus performance}

The Crocus model was run over the three distinct time periods and annual and seasonal SMBs were compared to measurements (Fig. 3). Correlations are significant in every case at the $95 \%$ confidence interval according to a Student's $t$ test.

Performance over both the period 2006-2010 and the recent period 2011-2015 is similar. Winter SMB correlations for the recent period are high - Nash-Sutcliffe coefficient (NS) $>0.72$, Fig. 3e and h (Nash and Sutcliffe, 1970). This high performance results from the use of annual multiplication factors to correct precipitation to fit with accumulation measurements. As a consequence, differences between measured and simulated winter SMBs (systematically lower than $0.5 \mathrm{mw}$.e.) are due to the interpolation method and some melting events which can occur over the accumulation period. For these two periods (2006-2010 and 2011-2015), summer SMB simulations were also in good agreement with measurements (NS > 0.85) in both accumulation and ablation areas (Fig. $3 f$ and i), indicating good performance of the model in simulating SMB changes over the ablation season. Due to both good winter SMB and summer SMB simulations, results at an annual scale (Fig. 3d and g) also showed the good performance of the model ( $\mathrm{NS}>0.67)$.

Regarding the period 1996-2005 (Fig. 3a-c), while correlations between measured and simulated SMBs are significant at the $95 \%$ confidence interval according to a Student's $t$ test, results indicate lower performance, especially for the simulation of the summer SMBs (Fig. 3c). Simulated summer SMBs and annual SMBs (Fig. 3a and c) are overestimated for very negatives summer SMBs observed in 2002/2003 in the ablation area. 

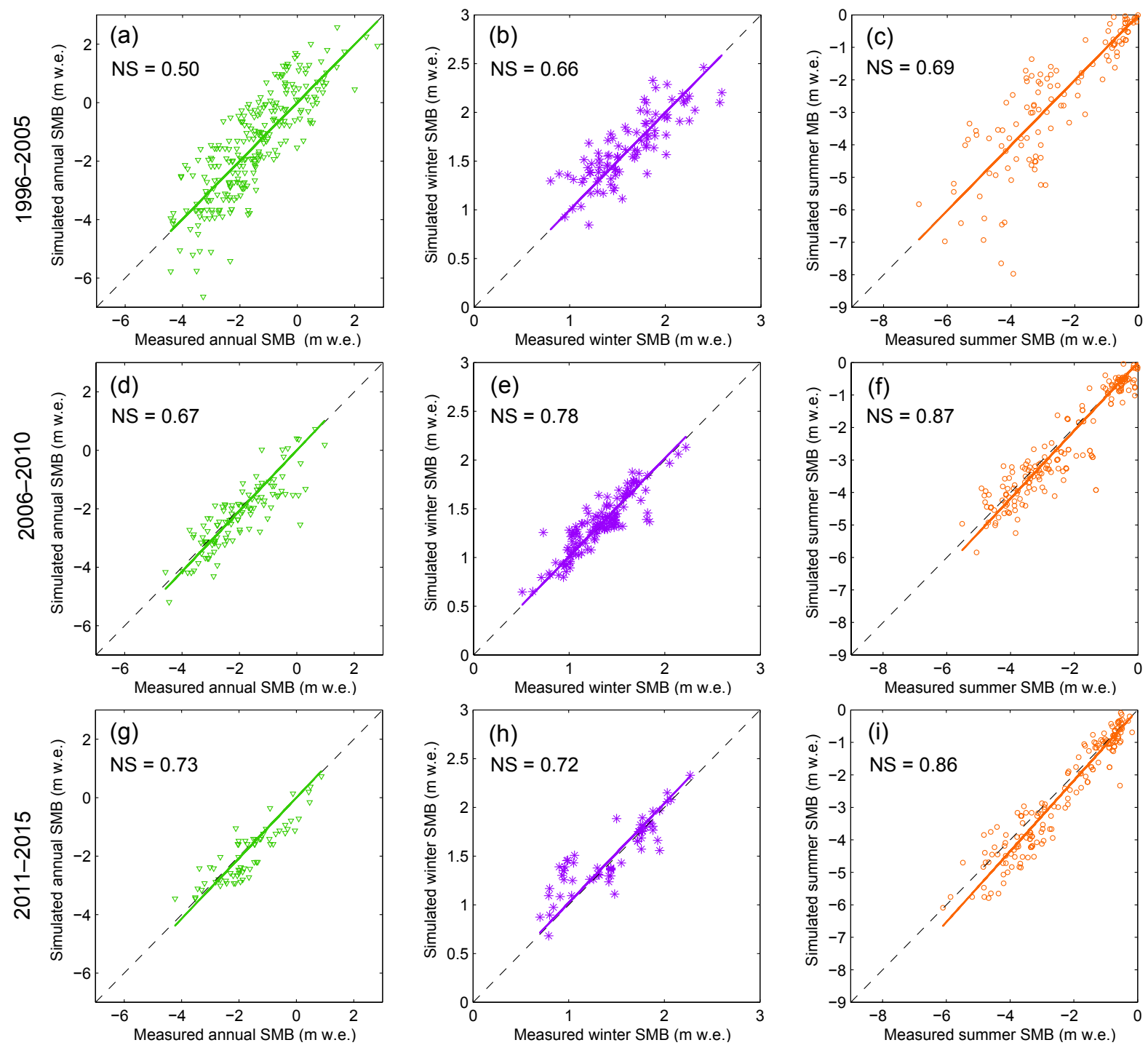

Figure 3. Comparisons between simulated and measured SMBs (mw.e.) at each measurement point over the 1996-2005 (in situ meteorological measurements not available; a-c), 2006-2010 (in situ meteorological measurements available on the moraine and on the glacier; d-f) and 2011-2015 (in situ meteorological measurements available on the moraine only; g-i) periods. The annual (a, d, g), winter (b, e, h) and summer (c, f, i) SMBs are shown in green, purple and orange, respectively. The Nash-Sutcliffe coefficient (NS) is indicated on each graph.

\subsubsection{Comparison with the temperature-index approach}

Over the period 2006-2015, results indicate better performance with the Crocus model (Fig. $4 \mathrm{a}$ and $\mathrm{b}$ ). Indeed, the ATI model underestimated the summer SMB values, when observed summer SMB is above $-2 \mathrm{~m}$ w.e., and in particular those corresponding to the accumulation area (Fig. 4a). This leads to a significant decrease in the correlations between measurements and simulations. However, when considering summer SMB measurements in the ablation area only, performance is similar for the two models (NS is 0.47 for Crocus and 0.51 for the ATI model).
In addition, the temporal evolution of the simulated summer SMBs over season is shown in Fig. 5. Daily summer SMB data simulated by both models are reported in each graph for different measurement points. Note that this was done for all years over the period 2006-2015, but only results for the year 2008 are represented here for the sake of clarity. For this year, results indicate very similar performance for the two models in the lower part of the ablation area (stakes 1 to 22) at the end of the season: the absolute mean difference of summer SMB is $0.13 \mathrm{mw}$ w.e. $\mathrm{yr}^{-1}$ (lower than the measurement uncertainty) and the maximum difference is $0.36 \mathrm{mw}$ we. $\mathrm{yr}^{-1}$. The same is true when we consider all the ablation season results (i.e. 2006-2015): the maximum 

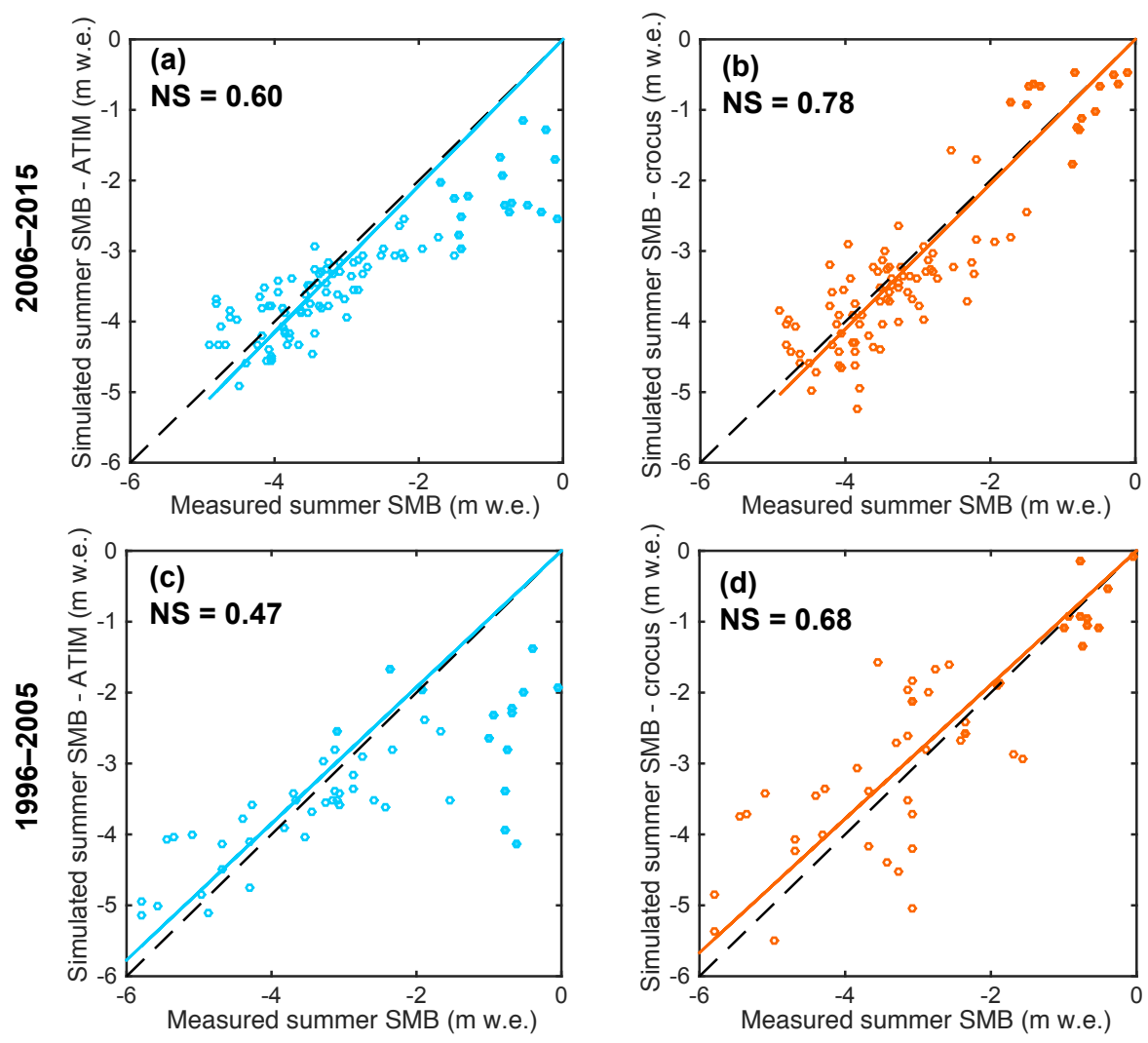

Figure 4. Correlations between simulated - blue (a, c) for the ATI model and orange (b, d) for the Crocus model - and measured summer SMBs at each stake of Saint-Sorlin Glacier over the 2006-2015 period (a, b) and the 1996-2005 period (c, d). Circles represent measurements in the ablation area and solid dots represent measurements in the accumulation area.

difference is $0.45 \mathrm{mw}$.e. $\mathrm{yr}^{-1}$. For the year 2008 , the ATI model simulates lower ablation compared to Crocus model during August in the lowest part of the glacier (e.g. stakes 20 and 22), and higher ablation during October (Fig. 5). However these results are specific to this year and these stakes. No systematic difference is observed.

In the accumulation area and close to the equilibrium line (e.g. stakes 27, 30), differences between the summer SMBs simulated by the two models (Fig. 5) are greater: the absolute mean difference of summer SMB is $0.56 \mathrm{mw}$.e. $\mathrm{yr}^{-1}$ and the maximum difference is $0.87 \mathrm{mw}$.e. $\mathrm{yr}^{-1}$. Considering all the years, the maximum difference is $1.91 \mathrm{mw}$.e. $\mathrm{yr}^{-1}$. Here again, there is no systematic difference, except that maximum differences are generally observed in June and October.

Over the period 1996-2005, considering all the point data over the entire glacier, Crocus performs better than the ATI model (Fig. 4c and d). Here again, summer SMBs simulated with the ATI model in the accumulation area are underestimated. On the other hand, when considering the ablation area only, results from the ATI model better fit the summer SMB measurements (NS is 0.36 for Crocus and 0.59 for the ATI model). Decreasing Crocus performance over the 19962005 period can be explained by the absence of AWS mea- surements to evaluate and validate the correction made on the wind speed and longwave forcing data.

Note that the ATI was calibrated over the period 20052015 and is stable over the 20 years of simulations, considering an uncertainty of $0.2 \mathrm{~m}$ w.e. (Réveillet et al., 2017). However, stability of the parameters over a period of more than two decades cannot be guaranteed.

\subsubsection{Annual mass balance sensitivity to seasonal mass balance}

The tests (described in Sect. 3.2.1) of the annual mass balance sensitivity to seasonal mass balance using the Crocus model were performed at seven stakes in the ablation area, ranging between 2700 and 2870 ma.s.l. For the sake of clarity, only the results for stake 10 (located at 2760 ma.s.l.) are presented in Fig. 6, but conclusions are similar for all the stakes.

Regarding the sensitivity of annual SMB to summer SMB (Fig. 6a), the results show that the simulated annual SMB was the least negative with 1995 summer conditions (green curve) and the most negative with 2003 summer conditions (red line). The difference in annual SMBs between these two extreme summers for stake 10 was $4.1 \mathrm{mw}$.e. $\mathrm{yr}^{-1}$ at the end 

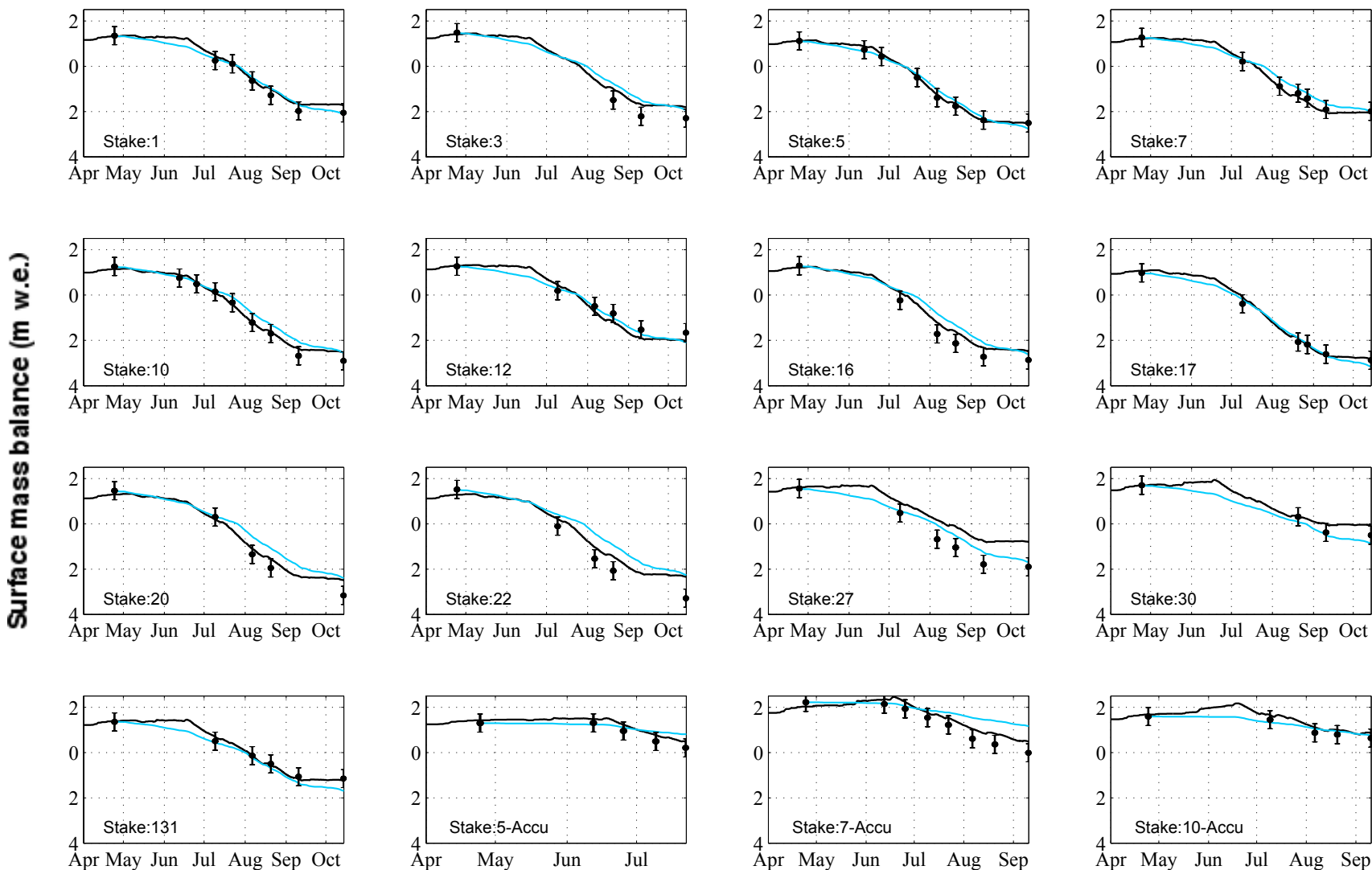

2008

Figure 5. Surface mass balance evolution at some selected measurement points of Saint-Sorlin Glacier over the hydrological year 20072008. Black lines represent the simulated SMB using Crocus model with corrected forcing. The blue curves show the simulation made with the ATI model using simulated winter SMB adjusted with measurements. Black dots represent the measurements with their uncertainties.
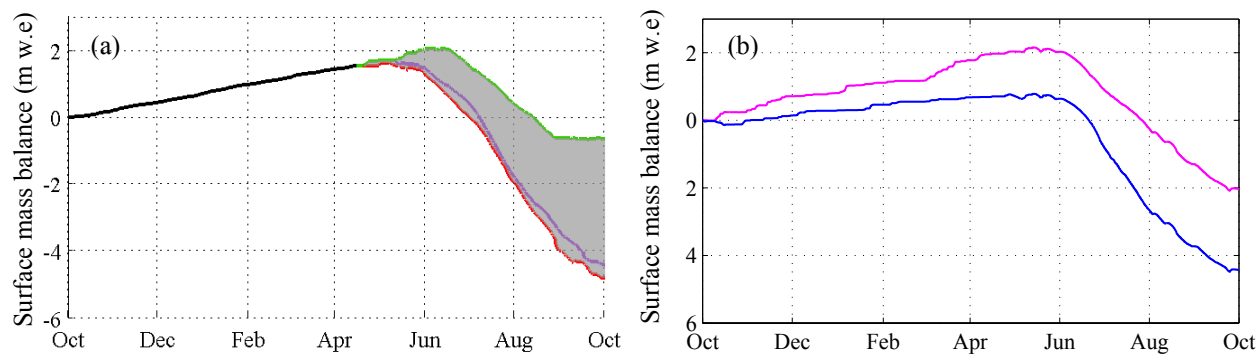

Figure 6. (a) Surface mass balance at stake 10, (2760 ma.s.1.) over one hydrological year, using averaged winter conditions and all summer conditions for the period 1995-2015. Red line represents simulation with 2003 summer conditions and the green line represents 1995 summer conditions. All the other years are included in the grey area. (b) Surface mass balance at stake 10, over one hydrological year, using averaged summer conditions (over 1996-2015), 2000-2001 winter conditions (pink) and 2008-2009 winter conditions (blue), representing the two extreme results.

of the hydrological year. Similar results are found for the other stakes: the mean difference is $4.4 \mathrm{~m}$ w.e. $\mathrm{yr}^{-1}$ with a SD of $0.41 \mathrm{mw}$.e. $\mathrm{yr}^{-1}$.

The sensitivity of annual SMB to winter SMB is illustrated by Fig. $6 \mathrm{~b}$. Note that for the sake of clarity, only the two ex- treme years of the time series - 2000-2001, highest winter SMB (pink line) and 2008-2009, lowest winter SMB (blue line) - are presented in Fig. 6b. The difference between these 2 years on 15 April is $1.2 \mathrm{mw}$.e. at stake 10 (and on average $1.1 \mathrm{~m}$ w.e. with a SD of $0.13 \mathrm{~m}$ w.e. considering all the 
stakes). Using the same summer conditions, the difference at the end of the hydrological year is $2.4 \mathrm{mw}$.e. (i.e. twice the difference at the end of the winter season). Here again results are similar for the all the stakes considered: the mean difference is $2.2 \mathrm{mw}$ w.e. $\mathrm{yr}^{-1}$ with a SD of $0.21 \mathrm{mw}$ w.e. $\mathrm{yr}^{-1}$.

The same test was performed using the extreme 2003 summer conditions instead of the mean summer conditions. In this case, the difference at the end of the hydrological year for all the stakes was considerably larger (mean of $3.4 \mathrm{~m}$ w.e., SD $0.45 \mathrm{mw}$.e. $\mathrm{yr}^{-1}$; results not shown). These results confirm that the annual SMB variability is mainly driven by the summer SMB variability (i.e. differences are larger when we considered a mean winter and all the summer conditions than the contrary). Nevertheless, the annual SMB appears to be very sensitive to the winter SMB, in particular for extreme years.

\subsection{Sensitivity of SMB to Crocus parameterization}

\subsubsection{Digital elevation model resolution and date}

Regarding the effect of the spatial resolution of the DEM (i.e. 50 vs. $200 \mathrm{~m}$ resolution grid), changes in winter SMB are negligible (NS coefficients are equal). Surprisingly, our results also indicate similar performance in simulating the summer SMB when using a 50 or $200 \mathrm{~m}$ resolution DEM (not shown here), even if changing the resolution impacts the calculation of slope and aspect and affects the incoming radiation computation (shadowing effect).

On the other hand, the comparison between the 1998 and 2014 DEMs shows surface elevation lowering ranging from 0 to $-52 \mathrm{~m}$ and an average slope increase from 0 to $6^{\circ}$, with larger slope changes found in the ablation area. The impact of these changes was evaluated for different areas. First, correlations between simulated and measured summer SMB were computed for all the stake measurements (in the accumulation and ablation areas), then for the stakes located in the ablation area only and finally for the stakes located in the lower part of the glacier tongue. The differences between the simulated and measured summer SMBs are reported in Table 2 (correlations are not statistically different). The highest differences between simulations and measurements are obtained for the stakes located in the lower part of the glacier tongue, using 1998 and 2007 DEMs (i.e. where geometric changes are the greatest). Simulations performed with 1998 and 2007 DEMs led to a mean difference in simulated summer SMBs of 0.19 m w.e. $\mathrm{yr}^{-1}$ ( $\sim 5 \%$ of the summer SMBs) and reached $0.64 \mathrm{mw}$.e. $\mathrm{yr}^{-1}$ for the lowest stakes $(\sim 15 \%$ of the summer SMBs and $\sim 20 \%$ of the annual SMBs). Simulations performed with 2007 and 2014 DEMs led to a mean difference of 0.15 w.e. $\mathrm{yr}^{-1}(<5 \%$ of the summer SMBs) and a maximum of 0.475 w.e. $\mathrm{yr}^{-1}$ for the lowest stakes. Note that the differences in simulated summer SMBs vs. measurements in the accumulation area are larger when considering the DEMs from 2014 and 2007 than with 1998
Table 2. NS efficiency coefficient for simulated summer mass balances with respect to measured values over the 2006-2010 period using different $200 \mathrm{~m}$ resolution DEMs. The evaluation was performed using all stake measurements, only stakes located in the ablation area and stakes located in the tongue of the glacier where geometry changes are larger.

\begin{tabular}{lccc}
\hline $\begin{array}{l}\text { DEM } \\
\text { date }\end{array}$ & $\begin{array}{c}\text { NS (all } \\
\text { stakes) }\end{array}$ & $\begin{array}{c}\text { NS (stakes } \\
\text { of the } \\
\text { ablation } \\
\text { area) }\end{array}$ & $\begin{array}{c}\text { NS (stakes } \\
\text { close to } \\
\text { the tongue) }\end{array}$ \\
\hline 1998 & 0.87 & 0.41 & 0.79 \\
2007 & 0.87 & 0.42 & 0.85 \\
2014 & 0.86 & 0.47 & 0.82 \\
\hline
\end{tabular}

and 2007 DEMs and can reach 0.38 mw.e. $\mathrm{yr}^{-1}(\sim 20 \%$ of the summer SMBs and $\sim 25 \%$ of the annual SMBs). Despite changes in glacier surface topography over the entire study period, such changes only affect the simulated summer SMB (i.e. considering changes larger that measurement uncertainty) for a limited number of individual stakes (maximum 5). Considering the entire glacier, these changes in the simulated summer SMB are negligible as the mean is lower than the measurement uncertainty.

\subsubsection{Meteorological inputs}

An important question is whether the Crocus model forced with SAFRAN reanalysis data could be used on a large set of glaciers or over a long time period without in situ meteorological measurements available to evaluate or correct the atmospheric forcing. The sensitivity of the model to the corrections made on the meteorological forcing described in Sect. 2.3.4 and summarized in Fig. 2 is presented below. Uncertainties are calculated over the 2006-2010 period, at each measurement point of the glacier.

\section{Sensitivity to precipitation correction}

SAFRAN precipitation was corrected annually using an extensive data set of winter SMBs on Saint-Sorlin Glacier. Here we test different approaches to correct SAFRAN precipitation to consider the case when such extensive measurements are not available.

First, as already mentioned in previous papers (e.g. Gerbaux et al., 2005; Dumont et al., 2012), using raw SAFRAN precipitation leads to an underestimation of the winter SMB due to the lack of observations in high-altitude areas and the complexity of considering local effects such as wind transport. Using raw SAFRAN precipitation data leads to a very low NS coefficient for simulated winter SMBs with respect to observed values. This difference in terms of winter SMB also strongly impacts the performance in simulating summer SMB and annual SMB (Table 3). 
Table 3. NS efficiency coefficients for simulated surface mass balances with respect to measured values over the 2006-2010 period. Simulations were performed using three different approaches to correct precipitation and were evaluated for the winter SMB, summer SMB and annual SMB.

\begin{tabular}{lrrr}
\hline & $\begin{array}{r}\text { NS for } \\
\text { ASMB }\end{array}$ & $\begin{array}{r}\text { NS for } \\
\text { WSMB }\end{array}$ & $\begin{array}{r}\text { NS for } \\
\text { Summer } \\
\text { SMB }\end{array}$ \\
\hline Annual map of factors & 0.67 & 0.78 & 0.87 \\
No adjustment & -0.01 & -0.03 & 0.23 \\
Constant factor: 1.73 & 0.47 & 0.09 & 0.75 \\
Mean factors for 1996-2015 period & 0.49 & 0.15 & 0.77 \\
\hline
\end{tabular}

Second, based on the results provided by a method using a single mean correction factor over the entire glacier surface area, equal to 1.73 for Saint-Sorlin Glacier, there is a significant decrease in the correlation between measured and simulated winter SMBs and lower performance in the simulation of summer SMBs.

Finally, the use of an averaged spatialized map of multiplicative factors also showed a decrease in the efficiency of both winter and summer SMB estimates (NS decreased from 0.78 to 0.15 and from 0.87 to 0.77 , respectively).

These results suggest that, for Saint-Sorlin Glacier, the accuracy of the seasonal SMB computation is affected by the spatial and temporal aspects of the precipitation adjustment. This highlights the importance of considering local effects driving the spatio-temporal variability of the winter SMB, such as wind transport and sublimation.

\section{Sensitivity to incoming longwave radiation}

The impact of the incoming longwave radiation corrections is significant and considerably affects the simulated summer SMB. A good example is the 2007-2008 hydrological year shown in Fig. 7 (pink curves). Because the SAFRAN raw incoming longwave radiation is overestimated for low cloudiness conditions (by about $30 \%$ ), the correction leads to a decrease in the energy available for melt and thus a less negative summer SMB. Simulations performed with and without longwave correction indicate a mean difference (computed with all available measurements over the 2006-2010 period) at the end of the season of $0.54 \mathrm{mw}$.e. $\mathrm{yr}^{-1}$ (with a SD equal to $0.60 \mathrm{mw}$.e. $\mathrm{yr}^{-1}$ ). Hence, not considering the incoming longwave radiation correction leads to a significant decrease in the NS coefficient (see Table 4). Note also that Sautner and Obleitner (2015) found a high sensitivity of the Crocus snowpack model to errors of incident longwave radiation over glaciers in Svalbard.

\section{Sensitivity to wind speed correction}

The impact of wind speed on the simulated mass balance was assessed over the period 2006-2010 using the wind
Table 4. NS efficiency coefficients for simulated surface mass balances with respect to measured values over the 2006-2010 period. Simulations were performed with and without correction of the meteorological forcing from SAFRAN.

\begin{tabular}{lccc}
\hline & $\begin{array}{c}\text { NS for } \\
\text { ASMB }\end{array}$ & $\begin{array}{c}\text { NS for } \\
\text { WSMB }\end{array}$ & $\begin{array}{c}\text { NS for } \\
\text { Summer } \\
\text { SMB }\end{array}$ \\
\hline SAFRAN with corrected data & 0.67 & 0.78 & 0.86 \\
Without LW correction & 0.36 & 0.73 & 0.65 \\
Without wind speed correction & 0.27 & 0.59 & 0.71 \\
\hline
\end{tabular}

speed data from $\mathrm{AWS}_{\mathrm{m}}$ and from SAFRAN (Fig. 7, "example for the 2007-2008 hydrological year", black and blue curves). The mean difference at the end of the hydrological year, considering all stakes, is $-0.70 \mathrm{mw}$ w.e. $\mathrm{yr}^{-1}$ (with a SD equal to $0.76 \mathrm{mw}$.e. $\mathrm{yr}^{-1}$ ), with a maximum difference of $-1.72 \mathrm{mw}$ w.e. $\mathrm{yr}^{-1}$ (stake 16 in Fig. 7). The use of uncorrected wind speed data significantly decreases the performance of the annual SMB simulations (the NS coefficient decreases from 0.67 to 0.27 , Table 4 ).

The influence of wind speed and direction on snow accumulation variability during and after snowfall events is widely recognized (e.g. Winstral and Marks, 2002). Our results emphasize the important role of wind speed in energy balance exchanges and its impact on the SMB (Fig. 7). Indeed, wind impacts the snow surface density through snow compaction (e.g. Vionnet et al., 2012) and the turbulent fluxes (e.g. Litt et al., 2017). In fact, each component of the turbulent fluxes ( $H$ and LE) simulated with original SAFRAN wind data is lower than those simulated with the measured wind. For instance, the mean value of $H$ computed over summer 2006 is equal to $7.2 \mathrm{~W} \mathrm{~m}^{-2}$ (with a SD of $10.7 \mathrm{~W} \mathrm{~m}^{-2}$ ) when simulated with SAFRAN wind data, compared to $22.2 \mathrm{~W} \mathrm{~m}^{-2}$ (with a SD of $37.8 \mathrm{~W} \mathrm{~m}^{-2}$ ) when using measured wind speed.

Considering wind speed data from $\mathrm{AWS}_{\mathrm{m}}$ leads to an increase in the snow density of about $50 \mathrm{~kg} \mathrm{~m}^{-3}$ for the upper layers of the snowpack when density is lower than $300 \mathrm{~kg} \mathrm{~m}^{-3}$. Above this value, densities are similar with and without wind speed correction. The changes in snow density directly affect the thermal conductivity of the upper snow layers (Yen, 1981).

As a consequence, differences in snow density, and even more so in turbulent fluxes, due to wind speed correction have a considerable impact on surface temperature (Fig. 8). Over the period 2006-2010, the mean simulated snow surface temperature increases by $3.4^{\circ} \mathrm{C}$ using corrected wind speed (maximum increase of $20^{\circ} \mathrm{C}$ ) and the mean ice surface temperature increases by $2.7^{\circ} \mathrm{C}$ (maximum increase of $10^{\circ} \mathrm{C}$ ), with larger differences during the night.

Simulated surface temperatures were compared to measurements. During winter, when snow depth is sufficient $(\sim$ 

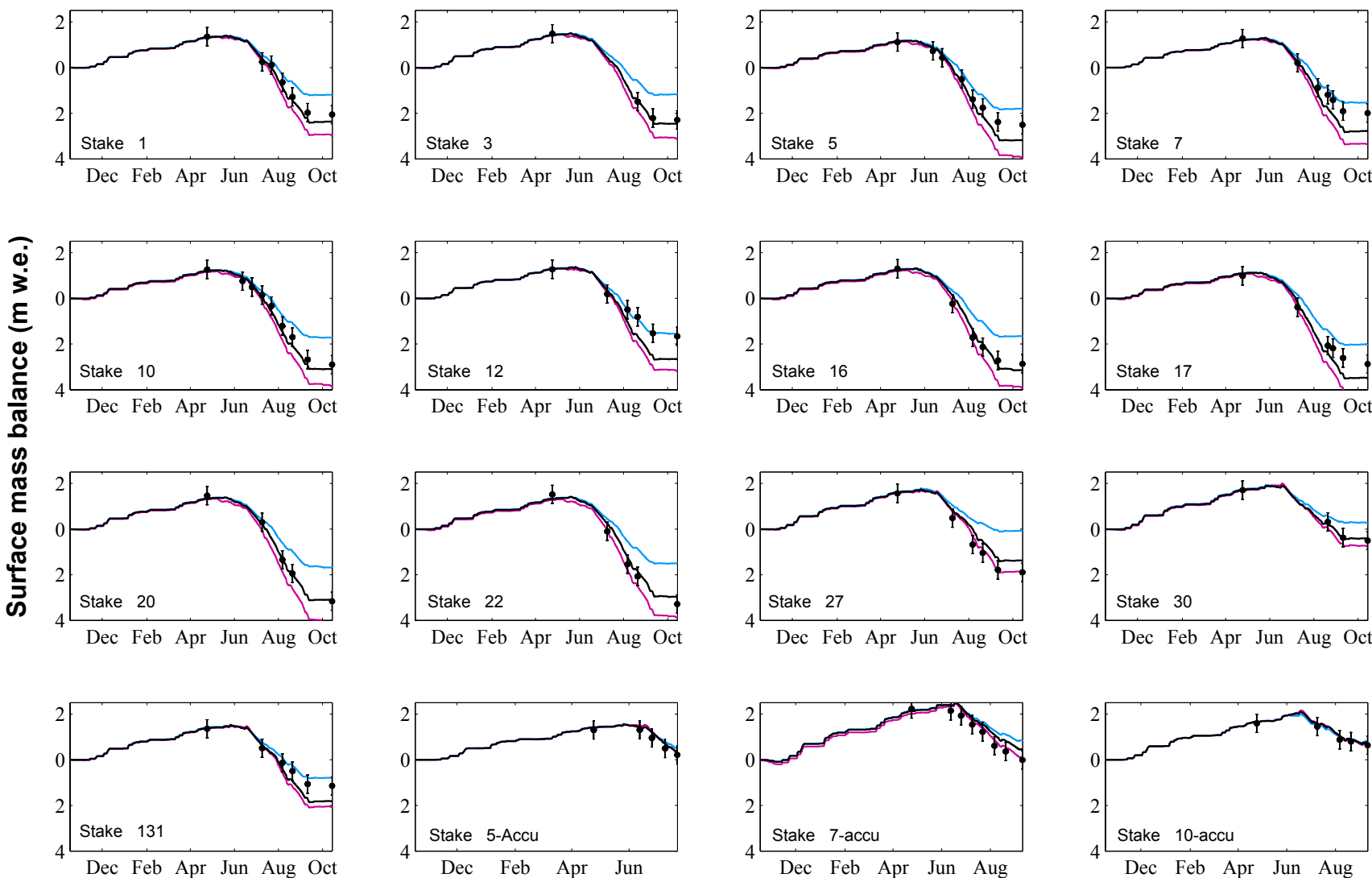

Hydological year 2007-2008

Figure 7. Surface mass balance (in mw.e.) at some selected measurement points in the accumulation (accu) and ablation areas of SaintSorlin Glacier (numbers refer to the stake numbers shown in Fig. 1) over the hydrological year 2007-2008 (from 17 October to 10 October). Black curves represent the simulated mass balance with corrected forcing (Sect. 2.3.4). Pink curves are the simulations without the incoming longwave radiation correction. Blue curves are the simulations without the wind speed correction. Black dots represent the measurements and their uncertainties.

$20 \mathrm{~cm}$ ) and energy balance is not affected by ground fluxes, outgoing LW measured at $\mathrm{AWS}_{\mathrm{m}}$ can provide the snow surface temperature using the Stefan-Boltzmann law (with an uncertainty of $1^{\circ} \mathrm{C}$ ). During summer, outgoing LW measurements from $\mathrm{AWS}_{\mathrm{g} 06}$ were used to compare simulated and measured surface temperatures. Figure 8 illustrates the impact of the wind correction on the simulated surface temperature and the comparison with measurements in 2006. Results indicated a significant increase in correlation between measured and simulated surface temperatures when corrected wind was considered (NS increase from -3.14 to 0.28 for the summer period and from -0.30 to 0.20 for the winter period). Nevertheless, even using corrected wind speed values, simulated surface temperatures are still lower than the measurements, especially over the winter period. Note that the surface temperature also has a feedback on the turbulent fluxes (e.g. an increase in ice/snow surface temperature can reduce the turbulent heat flux into the surface), leading to a complex relation between these variables.
During the winter season, surface temperatures (measured or simulated) are in any case too low for melting to occur and consequently the impact of the correction of wind speed on the winter SMB is negligible (Fig. 7). The impact of surface temperature can be first observed in spring: if surface temperature during the night is too low, the available energy during the day is used only to warm the snow layer and not for melting. A larger impact of the correction of wind on SMB can be observed during the second part of the summer in the ablation area (from about July, Fig. 7) when the surface is ice, indicating the importance of having wind speed measurements to compute turbulent fluxes.

\subsubsection{Sensitivity of Crocus parameters}

As mentioned in the previous section, even when considering measured wind speed, a difference persists between the measured and simulated surface temperatures. Sensitivity tests were performed to better understand the processes respon- 


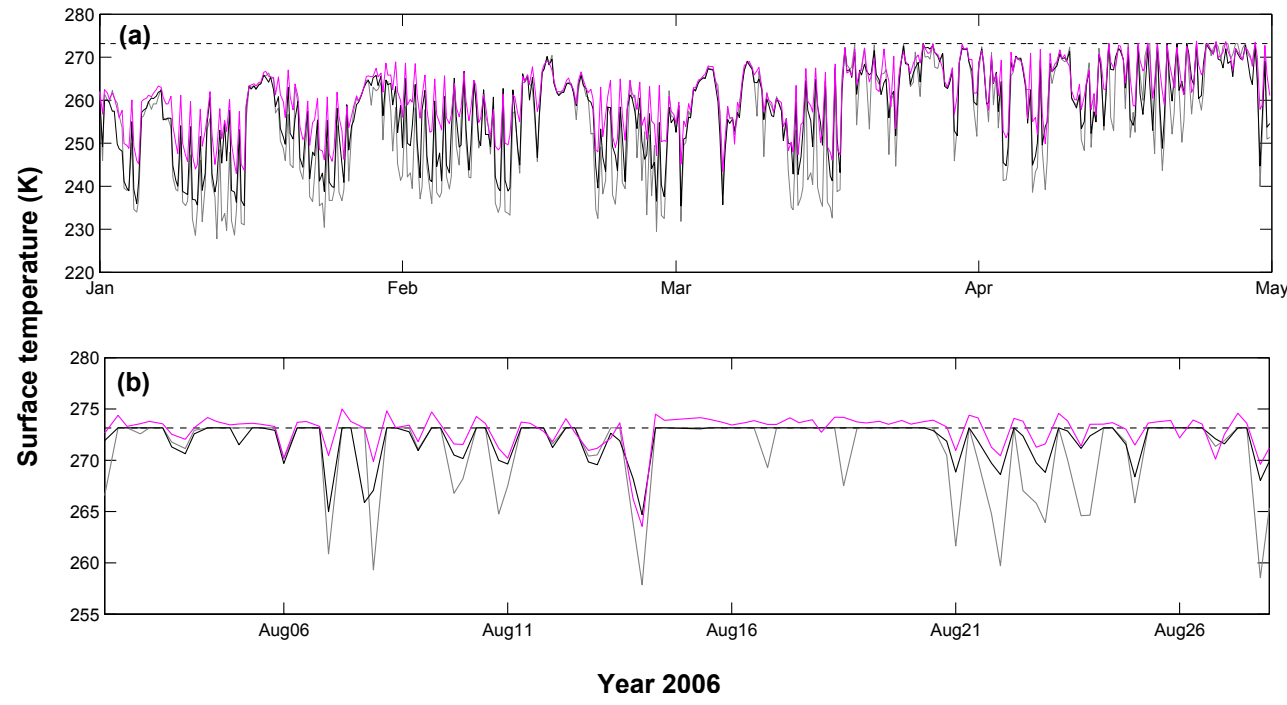

Figure 8. (a) Winter hourly surface temperature (snow surface) from January to May 2006, measured using outgoing LW radiation at $\mathrm{AWS}_{\mathrm{m}}$ (pink) and simulated without (grey) and with (black) wind speed correction. (b) Summer hourly surface temperature measured using outgoing LW at $\mathrm{AWS}_{\mathrm{g} 06}$ (pink) and simulated without (grey) and with (black) wind speed correction from 9 July to 28 August 2006 . Dashed line corresponds to the melting point.

sible for this underestimation of simulated surface temperatures.

\section{Surface roughness length}

While feedback loops exist between turbulent fluxes and surface temperature, we attempted to assess the impact of effective roughness length values on both surface temperature and summer SMB. Considering that the values generally found in the literature for ice surfaces are most of the time in the range of 1 to $6 \mathrm{~mm}$ (e.g. Brock et al., 2006, Table 1; Smith et al., 2016) and can reach $80 \mathrm{~mm}$ for very rough glacier ice (Smeets et al., 1999), the tests were performed with ice values ranging between 1 and $100 \mathrm{~mm}$ (Fig. 9). Figure 9a illustrates a stronger impact for more negative SSBMs (corresponding to mainly ice ablation) than for the less negative summer SMBs (corresponding to snow ablation). This is confirmed by results shown in Fig. $9 \mathrm{~b}$ (one stake in the ablation zone) and c (one stake in the accumulation area). At the end of the hydrological season, there is a difference of SMB of $77 \%$ in the ablation area (ice surface) and $11 \%$ in the accumulation area (snow surface) between roughness values of 1 and 100. In fact, changing the roughness length considerably affects the simulated ice ablation (Fig. 9b) but the effect is limited on the simulated snow ablation (Fig. 9c), considering that the impact of other parameters such as albedo changes can be greater.

In this study, $z_{0}$ is calibrated to provide good agreement between the simulated and measured turbulent fluxes on the ice from 9 July to 28 August 2006 (Litt et al., 2017; see Sect. 2.3.2). For this, numerical experiments were performed using an ice roughness length $z_{0 \text { ice }}$ ranging from $10^{-5}$ to
$0.2 \mathrm{~m}$. The best simulation performed with Crocus was obtained with an ice roughness length $\left(z_{0 \text { ice }}\right)$ of $1 \mathrm{~mm}$. Note that $z_{0}$ was calibrated by fitting the simulated sum of $H$ and LE with the one calculated with the EC method. However, turbulent flux measurements are available over a short time period, only for one ablation season. As $z_{0}$ can vary considerably over time (including at daily timescales) and space (snow or ice surfaces), and due to the strong sensitivity of the model to this parameter and the large uncertainty in its determination, having in situ turbulent flux measurements over ice and snow surfaces, and covering various summer ablation seasons is very useful to properly calibrate $z_{0}$. In addition, uncertainty evaluation should be further investigated, for instance, by testing the surface renewal method to improve the scalar roughnesses estimation, or in considering stability corrections (Andreas, 1987).

\section{Ice albedo}

Albedo measurements were used to calibrate and validate the albedo range in the model. The correlation between daily albedo measurements and daily simulations is significant $\left(95 \%\right.$ confidence level (Student's $t$ test), $R^{2}=0.54$, RMSE $=0.23$ ). In particular, the transition date from snow surface to ice surface is well represented in the ablation area (difference lower than 5 days). Nevertheless, surface albedo is highly variable in time and space and validation was carried out at only two points (one in the ablation area and one in the accumulation area) over a short time period (3 months). Therefore, this variable was tested to evaluate its sensitivity.

Simulations to test Crocus parameter sensitivity to ice albedo were performed in the ablation area for the 2006 

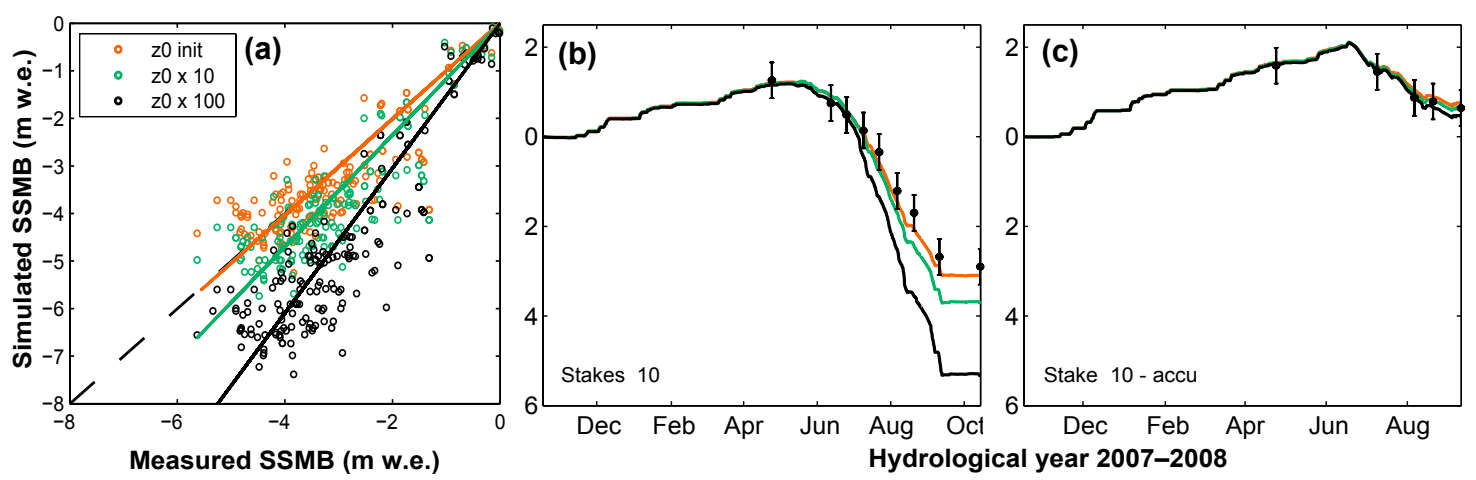

Figure 9. (a) Correlations between simulated and measured summer SMBs at each measurement point over the 2006-2010 period, using different roughness lengths. Surface mass balance evolution at one stake in the ablation area (b) and at one stake in accumulation area (c) over the hydrological year 2007-2008. SMB was simulated using different roughness length values for snow and ice $-z_{0 \text { ice }}=1 \mathrm{~mm}$ and $z_{\text {osnow }}=0.1 \mathrm{~mm}$ (orange), $z_{0 \text { ice }}=10 \mathrm{~mm}$ and $z_{0 \text { snow }}=1 \mathrm{~mm}$ (green), and $z_{0 \text { ice }}=100 \mathrm{~mm}$ and $z_{0 \text { snow }}=10 \mathrm{~mm}($ black$)$.

2010 period by changing the ice albedo of the spectral band $[0.3-0.8] \mu \mathrm{m}$ from 0.16 to 0.32 . For the sake of clarity, Fig. 10 illustrates the results for stake 10 for the hydrological year 2007-2008, but results are similar for the other stakes and over the other hydrological years. The difference in annual SMBs at the end of the hydrological year is $0.48 \mathrm{mw}$.e. $\mathrm{yr}^{-1}$ (17\% of the annual SMBs). Our results point out that this parameter needs to be properly calibrated with measurements on Saint-Sorlin Glacier to optimize model performance. However, model performance is possibly more sensitive to albedo parameterization for glaciers where radiation has a larger contribution to melt energy. Six et al. (2009, Table 3) showed that, during summer 2006, monthly mean fluxes of the energy balance were $80 \%$ for the net all-wave radiation $R$ and $20 \%$ for the turbulent fluxes. This monthly mean distribution can reach 70 and $30 \%$, respectively, on a daily timescale. For Zongo Glacier (Bolivia, $16^{\circ} \mathrm{S}$ ) the net all-wave radiation $R$ can represent $97 \%$ of the energy balance (Sicart et al., 2008).

\section{Liquid water content at the surface}

During melting events the simulated liquid water percolates through the snow layers when the liquid water volumetric content exceeds $5 \%$ of the pore volume (Vionnet et al., 2012). For ice, the porosity is set to 0 so the liquid water immediately flows off the glacier and cannot remain at the surface. The use of such parameterization on ice is questionable as water from ice melt or from shallow snow layer melt above ice can stay at the surface.

A sensitivity test was performed considering ice as a porous material able to store liquid water in $10 \%$ of its total volume. Note that this sensitivity test is an over-simplistic way to consider the presence or not of water at the ice surface. As the water percolates very quickly, the test can be performed over a very short time period during summer (a few days). For summer 2006 (not shown), a significant dif-

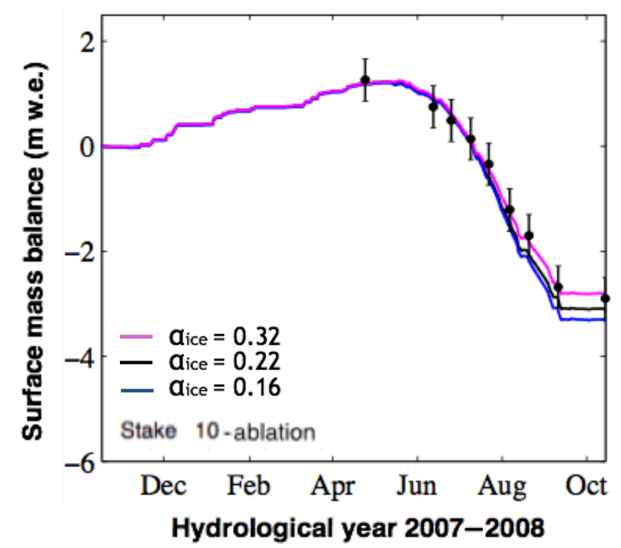

Figure 10. Surface mass balance evolution with an ice albedo calibrated at 0.16 (blue), 0.22 (black) and 0.32 (pink), at one stake in the ablation area over the hydrological year 2007-2008.

ference in the simulations was found for the surface temperature (maximum of $20^{\circ} \mathrm{C}$ difference) and surface mass balance (difference of $0.6 \mathrm{mw}$.e. after 15 days of simulation) when the possibility for water to be stored at the glacier surface was considered or not. While such a test is simplistic, it indicates the significant sensitivity of the energy budget to the presence of liquid water on the ice surface. This process deserves to be properly taken into account in Crocus when using the snow model over ice surfaces, as has been done for summer SMB simulations in Greenland with other models (e.g. Gallée and Duynkerke, 1997; Lefebre et al., 2003; Fettweis, 2007). 


\section{Conclusions}

This study has evaluated the performance of the Crocus snowpack model, which was fed with SAFRAN reanalysis data, thereby simulating seasonal and annual SMBs of SaintSorlin Glacier over the last 20 years. Using meteorological forcing adjusted with in situ measurements, our results show very good performance of the model to simulate summer SMB in both accumulation and ablation areas. Performance of the model is lower for the 1996-2005 period due to the absence of in situ meteorological measurements to adjust the forcing data.

Additionally, this study compared the performance of this energy balance model to an empirical approach using temperature and potential incoming solar radiation as inputs. Regarding simulations of summer SMB for the accumulation area, our results show better performance using the energy balance model, especially concerning simulations of snow and firn melting in the accumulation area. Regarding the ablation area of the glacier, the two approaches show similar performance when forced with meteorological data adjusted with nearby AWS measurements. When such measurements are not available in the vicinity of the glacier, performance of the empirical model in the ablation area is superior even though the physical processes are not properly represented. However, the temporal stability of the calibration parameters of the empirical approach needs to be assessed over a longer time period before using such an approach over several decades.

These conflicting conclusions about model performance in accumulation and ablation area emphasize greater importance of having meteorological data to correct the forcing in the ablation area. Indeed, in our sensitivity study using forcing data, the results demonstrate that the Crocus model is highly sensitive to wind speed, especially for ice melt simulations. Indeed, using in situ wind speed data instead of reanalysis data (where observed wind speed values larger than $10 \mathrm{~m} \mathrm{~s}^{-1}$ can be underestimated by a factor 2 or 3) led to an annual mass balance decrease of more than $1.7 \mathrm{mw}$ w.e. $\mathrm{yr}^{-1}$. Thus, without local wind speed measurements, the model's performance strongly decreases, even using wind speed data corrected via a quantile-mapping method. In addition this study confirms the findings by Dumont et al. (2012) concerning the importance of correcting the incoming longwave radiation from SAFRAN.

Model calibration represents an important step to improving model performance. According to the sensitivity study concerning model calibration, our results highlight the importance of calibrating the ice surface roughness using turbulent fluxes measurements. An increase in $z_{0 \text { ice }}$ by a factor of 10 can have an impact of $1.5 \mathrm{mw}$.e. $\mathrm{yr}^{-1}$ on ice melting. Regarding the ice albedo, while having in situ measurements to calibrate the model improved model performance; the sensitivity of summer SMB for this variable is lower than the sensitivity to wind speed over icy surfaces (the ice melt dif- ference reaches $0.48 \mathrm{mw}$ w.e. $\mathrm{yr}^{-1}$ when the ice albedo is divided by a factor 2 ). This could suggest a relatively low sensitivity to ice albedo change (due to dust or black carbon for example) for summer SMB variations in the future.

While both these approaches can provide good summer SMB simulations, winter SMB simulations need to be corrected using winter mass balance measurements. In any case, our results indicate a strong sensitivity of annual SMB to winter SMB. The understanding of the spatio-temporal variability of accumulation processes at the glacier surface needs to be more fully investigated in future work.

In conclusion, our study reveals the major role of wind speed, which controls the magnitude of turbulent fluxes, on melting. The results highlight a very serious obstacle for the modelling of future glacier mass balances, as this meteorological variable is highly unpredictable. Our results also suggest that the sensitivity of annual mass balance to accumulation and wind speed parameters is of primary significance, as compared to the sensitivity to snow and ice albedo changes. However, as such data are still difficult to represent in climatic models, the accuracy of their predictions are also questionable (e.g. Terzago et al., 2017). We thus suggest a careful use of the physical approach for future long-term simulations, considering the uncertainties. Nevertheless, despite these limitations for future simulations, this physical model remains crucial to study and understand physical processes and interactions between atmospheric variables and ablation. Otherwise, although empirical approaches based on simple meteorological variables also have serious drawbacks, they could be more appropriate for simulations of glaciers in the future, especially to simulate summer SMB in ablation areas, bearing in mind the lack of availability of reliable information on future meteorological variables and surface roughness.

Data availability. Part of the data used in this paper (seasonal mass balances and automatic weather station data) are from the Alpine GLACIOCLIM observatory and can be accessed at https: //glacioclim.osug.fr. For access to Safran data, please contact Samuel Morin or Marie Dumont. Data were processed using the Crocus model. This algorithm can be accessed by contacting their administrator, Marie Dumont or Matthieu Laffaysse.

Supplement. The supplement related to this article is available online at: https://doi.org/10.5194/tc-12-1367-2018-supplement.

Competing interests. The authors declare that they have no conflict of interest.

Acknowledgements. This study was conducted in the context of the French Service d'Observation GLACIOCLIM (https://glacioclim.osug.fr). We would like to thank everyone 
who helped in collecting data during these glacier field campaigns. Most of the computations presented in this paper were performed using the Froggy platform of the CIMENT infrastructure (https://ciment.ujf-grenoble.fr), which is supported by the Rhône-Alpes region (grant CPER07_13 CIRA). The work was made possible by the contributions of Labex OSUG@2020 (Investissements d'avenir - ANR10 LABX56), the ANR programme TAG 05-JCJC-0135 (conducted by Jean Emmanuel Sicart) and the French Research Ministry. We thank Yves Durand and Gérald Giraud (CNRM/CEN) for providing the SAFRAN data. Finally we acknowledge the editor and the two anonymous reviewers for detailed comments and helpful suggestions on previous versions of the manuscript.

Edited by: Valentina Radic

Reviewed by: two anonymous referees

\section{References}

Andreas, E. L.: A theory for scalar roughness and the scalar transfer coefficient over snow and sea ice, Bound.-Lay. Meteorol., 38, 159-184, 1987.

Braithwaite, R. J. and Olesen, O. B.: Calculation of Glacier Ablation from Air Temperature, West Greenland, in: Glacier Fluctuations and Climatic Change, edited by: Oerlemans, J., Springer Netherlands, Dordrecht, 219-233, 1989.

Brock, B. W., Willis, I. C., and Sharp, J. M.: Measurement and parameterization of aerodynamic roughness length variations at Haut Glacier d'Arolla, Switzerland, J. Glaciol., 52, 281-297, https://doi.org/10.3189/172756506781828746, 2006.

Brun, E., Martin, E., Simon, V., Gendre, C., and Coleou, C.: An energy and mass model of snow cover suitable for operational avalanche forecasting, J. Glaciol., 35, 333-342, 1989.

Brun, E., David, P., Sudul, M., and Brunot, G.: A numerical model to simulate snow-cover stratigraphy for operational avalanche forecasting, J. Glaciol., 38, 13-22, 1992.

Brutsaert, W.: Evaporation into the Atmosphere: Theory, History and application, D. Reidel, Hingham, Mass, 1982.

Carenzo, M., Pellicciotti, F., Rimkus, S., and Burlando, P.: Assessing the transferability and robustness of an enhanced temperatureindex glacier-melt model, J. Glaciol., 55, 258-274, https://doi.org/10.3189/002214309788608804, 2009.

Cuffey, K. M. and Paterson, W. S. B.: The physics of glaciers, Academic Press, Cambridge, Massachusetts, USA, 2010.

Cullen, N. J. and Conway, J. P.: A 22 month record of surface meteorology and energy balance from the ablation zone of Brewster Glacier, New Zealand, J. Glaciol., 61, 931-946, https://doi.org/10.3189/2015JoG15J004, 2015.

Déqué, M.: Frequency of precipitation and temperature extremes over France in an anthropogenic scenario: Model results and statistical correction according to observed values, Global Planet. Change, 57, 16-26, 2007.

Dumont, M., Durand, Y., Arnaud, Y., and Six, D.: Variational assimilation of albedo in a snowpack model and reconstruction of the spatial mass-balance distribution of an alpine glacier, J. Glaciol., 58, 151-164, https://doi.org/10.3189/2012JoG11J163, 2012.

Durand, Y., Laternser, M., Giraud, G., Etchevers, P., Lesaffre, B., and Mérindol, L.: Reanalysis of $44 \mathrm{Yr}$ of Cli- mate in the French Alps (1958-2002): Methodology, Model Validation, Climatology, and Trends for Air Temperature and Precipitation, J. Appl. Meteorol. Clim., 48, 429-449, https://doi.org/10.1175/2008JAMC1808.1, 2009.

Fettweis, X.: Reconstruction of the 1979-2006 Greenland ice sheet surface mass balance using the regional climate model MAR, The Cryosphere, 1, 21-40, https://doi.org/10.5194/tc-1-21-2007, 2007.

Gabbi, J., Carenzo, M., Pellicciotti, F., Bauder, A., and Funk, M.: A comparison of empirical and physically based glacier surface melt models for long-term simulations of glacier response, J. Glaciol., 60, 1140-1154, https://doi.org/10.3189/2014JoG14J011, 2014.

Gallée, H. and Duynkerke, P. G.: Air-snow interactions and the surface energy and mass balance over the melting zone of west greenland during the greenland ice margin experiment, J. Geophys. Res., 102, 13813-13824, https://doi.org/10.1029/96JD03358, 1997.

Gerbaux, M., Genthon, C., Etchevers, P., Vincent, C., and Dedieu, J. P.: Surface mass balance of glaciers in the French Alps: distributed modeling and sensitivity to climate change, J. Glaciol., 51, 561-572, https://doi.org/10.3189/172756505781829133, 2005.

Gobiet, A., Suklitsch, M., and Heinrich, G.: The effect of empiricalstatistical correction of intensity-dependent model errors on the temperature climate change signal, Hydrol. Earth Syst. Sci., 19, 4055-4066, https://doi.org/10.5194/hess-19-4055-2015, 2015.

Gromke, C., Manes, C., Walter, B., Lehning, M., and Guala, M.: Aerodynamic Roughness Length of Fresh Snow, Bound.Lay. Meteorol., 141, 21-34, https://doi.org/10.1007/s10546-0119623-3, 2011.

Hock, R.: A distributed temperature-index ice- and snowmelt model including potential direct solar radiation, J. Glaciol., 45, 101$111,1999$.

Hock, R.: Temperature index melt modelling in mountain areas, J. Hydrol., 282, 104-115, https://doi.org/10.1016/S00221694(03)00257-9, 2003.

Huss, M., Funk, M., and Ohmura, A.: Strong Alpine glacier melt in the 1940 s due to enhanced solar radiation, Geophys. Res. Lett., 36, L23501, https://doi.org/10.1029/2009GL040789, 2009.

IPCC: Climate Change 2013: The Physical Science Basis, in: Contribution of Working Group I to the Fifth Assessment, Report of the Intergovernmental Panel on Climate Change, edited by: Stocker, T. F., Qin, D., Plattner, G. K., Tignor, M., Allen, S. K., Boschung, J., Nauels, A., Xia, Y., Bex, V., and Midgley, P. M., Cambridge University Press, Cambridge, UK and New York, NY, USA, 2013.

Lafaysse, M., Hingray, B., Etchevers, P., Martin, E., and Obled, C.: Influence of spatial discretization, underground water storage and glacier melt on a physically-based hydrological model of the Upper Durance River basin, J. Hydrol., 403, 116-129, https://doi.org/10.1016/j.jhydrol.2011.03.046, 2011.

Lefebre, F., Gallée, H., van Ypersele, J.-P., and Greuell, W. : Modeling of snow and ice melt at ETH Camp (West Greenland): A study of surface albedo, J. Geophys. Res., 108, 4231, https://doi.org/10.1029/2001JD001160, 2003.

Lehning, M., Bartelt, P., Brown, B., Russi, T., Stöckli, U., and Zimmerli, M.: Snowpack model calculations for avalanche warning based upon a new network of weather and snow stations, Cold 
Reg. Sci. Technol., 30, 145-157, https://doi.org/10.1016/S0165232X(99)00022-1, 1999.

Lejeune, Y., Bouilloud, L., Etchevers, P., Wagnon, P., Chevallier, P., Sicart, J. E., Martin, E., and Habets, F.: Melting of Snow Cover in a Tropical Mountain Environment in Bolivia: Processes and Modeling, J. Hydrometeorol., 8, 922-937, https://doi.org/10.1175/JHM590.1, 2007.

Lejeune, Y., Bertrand, J. M., Wagnon, P., and Morin, S.:, A physically based model of the year-round surface energy and mass balance of debris-covered glaciers, J. Glaciol., 59, 327-344, 2013.

Litt, M., Sicart, J.-E., Six, D., Wagnon, P., and Helgason, W. D.: Surface-layer turbulence, energy balance and links to atmospheric circulations over a mountain glacier in the French Alps, The Cryosphere, 11, 971-987, https://doi.org/10.5194/tc11-971-2017, 2017.

MacDougall, A. H. and Flowers, G. E.: Spatial and Temporal Transferability of a Distributed Energy-Balance Glacier Melt Model, J. Climate, 24, 1480-1498, https://doi.org/10.1175/2010JCLI3821.1, 2011.

Masson, V., Le Moigne, P., Martin, E., Faroux, S., Alias, A., Alkama, R., Belamari, S., Barbu, A., Boone, A., Bouyssel, F., Brousseau, P., Brun, E., Calvet, J.-C., Carrer, D., Decharme, B., Delire, C., Donier, S., Essaouini, K., Gibelin, A.-L., Giordani, H., Habets, F., Jidane, M., Kerdraon, G., Kourzeneva, E., Lafaysse, M., Lafont, S., Lebeaupin Brossier, C., Lemonsu, A., Mahfouf, J.-F., Marguinaud, P., Mokhtari, M., Morin, S., Pigeon, G., Salgado, R., Seity, Y., Taillefer, F., Tanguy, G., Tulet, P., Vincendon, B., Vionnet, V., and Voldoire, A.: The SURFEXv7.2 land and ocean surface platform for coupled or offline simulation of earth surface variables and fluxes, Geosci. Model Dev., 6, 929-960, https://doi.org/10.5194/gmd-6-929-2013, 2013.

Mölg, T. and Kaser, G.: A new approach to resolving climate-cryosphere relations: Downscaling climate dynamics to glacier-scale mass and energy balance without statistical scale linking, J. Geophys. Res., 116, D16101, https://doi.org/10.1029/2011JD015669, 2011.

Nash, J. E. and Sutcliffe, J. V.: River flow forecasting through conceptual models part I - A discussion of principles, J. Hydrol., 10, 282-290, https://doi.org/10.1016/0022-1694(70)90255-6, 1970.

Obleitner, F. and Lehning, M.: Measurement and simulation of snow and superimposed ice at the Kongsvegen glacier, Svalbard (Spitzbergen), J. Geophys. Res., 109, D04106, https://doi.org/10.1029/2003JD003945, 2004.

Oerlemans, J. and Klok, E. J.: Energy Balance of a Glacier Surface: Analysis of Automatic Weather Station Data from the Morteratschgletscher, Switzerland, Arct. Antarct. Alp. Res., 34, 477485, https://doi.org/10.2307/1552206, 2002.

Oerlemans, J., Giesen, R. H., and Van Den Broeke, M. R.: Retreating alpine glaciers: increased melt rates due to accumulation of dust (Vadret da Morteratsch, Switzerland), J. Glaciol., 55, 729736, https://doi.org/10.3189/002214309789470969, 2009.

Pellicciotti, F., Brock, B., Strasser, U., Burlando, P., Funk, M., and Corripio, J.: An enhanced temperature-index glacier melt model including the shortwave radiation balance: development and testing for Haut Glacier d'Arolla, Switzerland, J. Glaciol., 51, 573587, https://doi.org/10.3189/172756505781829124, 2005.

Rabatel, A., Dedieu, J. P., and Vincent, C.: Spatio-temporal changes in glacier-wide mass balance quantified by optical remote sensing on, 30 glaciers in the French Alps for the period 1983-2014, J. Glaciol., 62, 1153-1166, https://doi.org/10.1017/jog.2016.113, 2016.

Réveillet, M., Vincent, C., Six, D., and Rabatel, A.: Which empirical model is best suited to simulate glacier mass balances?, J. Glaciol., 63, 39-54, https://doi.org/10.1017/jog.2016.110, 2017.

Sauter, T. and Obleitner, F.: Assessing the uncertainty of glacier mass-balance simulations in the European Arctic based on variance decomposition, Geosci. Model Dev., 8, 3911-3928, https://doi.org/10.5194/gmd-8-3911-2015, 2015.

Senese, A., Diolaiuti, G., Mihalcea, C., and Smiraglia, C.: Energy and Mass Balance of Forni Glacier (Stelvio National Park, Italian Alps) from a Four-Year Meteorological Data Record, Arct. Antarct. Alp. Res., 44, 122-134, https://doi.org/10.1657/19384246-44.1.122, 2012.

Sicart, J. E., Hock, R., and Six, D.: Glacier melt, air temperature, and energy balance in different climates: The Bolivian Tropics, the French Alps, and northern Sweden, J. Geophys. Res., 113, D24113, https://doi.org/10.1029/2008JD010406, 2008.

Sicart, J. E., Hock, R., Ribstein, P., Litt, M., and Ramirez, E.: Analysis of seasonal variations in mass balance and meltwater discharge of the tropical Zongo Glacier by application of a distributed energy balance model, J. Geophys. Res., 116, D13105, https://doi.org/10.1029/2010JD015105, 2011.

Six, D. and Vincent, C.: Sensitivity of mass balance and equilibrium-line altitude to climate change in the French Alps, J. Glaciol., 60, 867-878, https://doi.org/10.3189/2014JoG14J014, 2014.

Six, D., Wagnon, P., Sicart, J. E., and Vincent, C.: Meteorological controls on snow and ice ablation for two contrasting months on Glacier de Saint-Sorlin, France, Ann. Glaciol., 50, 66-72, https://doi.org/10.3189/172756409787769537, 2009.

Smeets, C. J. P. P., Duynkerke, P., and Vugts, H.: Observed wind profiles and turbulence fluxes over an ice surface with changing surface roughness, Bound.-Lay. Meteorol., 92, 99-121, 1999.

Smith, M. W., Quincey, D. J., Dixon, T., Bingham, R. G., Carrivick, J. L., Irvine-Fynn, T. D. L., and Rippin, D. M.: Aerodynamic roughness of ice surfaces derived from high resolution topographic data, J. Geophys. Res., 121, 748-766, https://doi.org/10.1002/2015JF003759, 2016.

Terzago, S., von Hardenberg, J., Palazzi, E., and Provenzale, A.: Snow water equivalent in the Alps as seen by gridded data sets, CMIP5 and CORDEX climate models, The Cryosphere, 11, 1625-1645, https://doi.org/10.5194/tc-11-1625-2017, 2017.

Thibert, E., Blanc, R., Vincent, C., and Eckert, N.: Glaciological and volumetric mass-balance measurements: error analysis over 51 years for Glacier de Sarennes, French Alps, J. Glaciol., 54, 522-532, https://doi.org/10.3189/002214308785837093, 2008.

Tribbeck, M. J., Gurney, R. J., Morris, E. M., and Pearson, D. W. C.: A new Snow-SVAT to simulate the accumulation and ablation of seasonal snow cover beneath a forest canopy, J. Glaciol., 50, 171-182, https://doi.org/10.3189/172756504781830187, 2004.

Vincent, C.: Influence of climate change over the 20th Century on four French glacier SMBs, J. Geophys. Res., 107, 4-12, https://doi.org/10.1029/2001JD000832, 2002.

Vionnet, V., Brun, E., Morin, S., Boone, A., Faroux, S., Le Moigne, P., Martin, E., and Willemet, J.-M.: The detailed snowpack scheme Crocus and its implementation in SURFEX v7.2, Geosci. Model Dev., 5, 773-791, https://doi.org/10.5194/gmd-5773-2012, 2012. 
Winstral, A. and Marks, D.: Simulating wind fields and snow redistribution using terrain-based parameters to model snow accumulation and melt over a semi-arid mountain catchment, Hydrol. Process., 16, 3585-3603, https://doi.org/10.1002/hyp.1238, 2002.
Yen, Y. C.: Review of thermal properties of snow, ice and sea ice, Tech. rep., DTIC Document, CRREL report, Hanover, USA, 27 pp., 1981. 